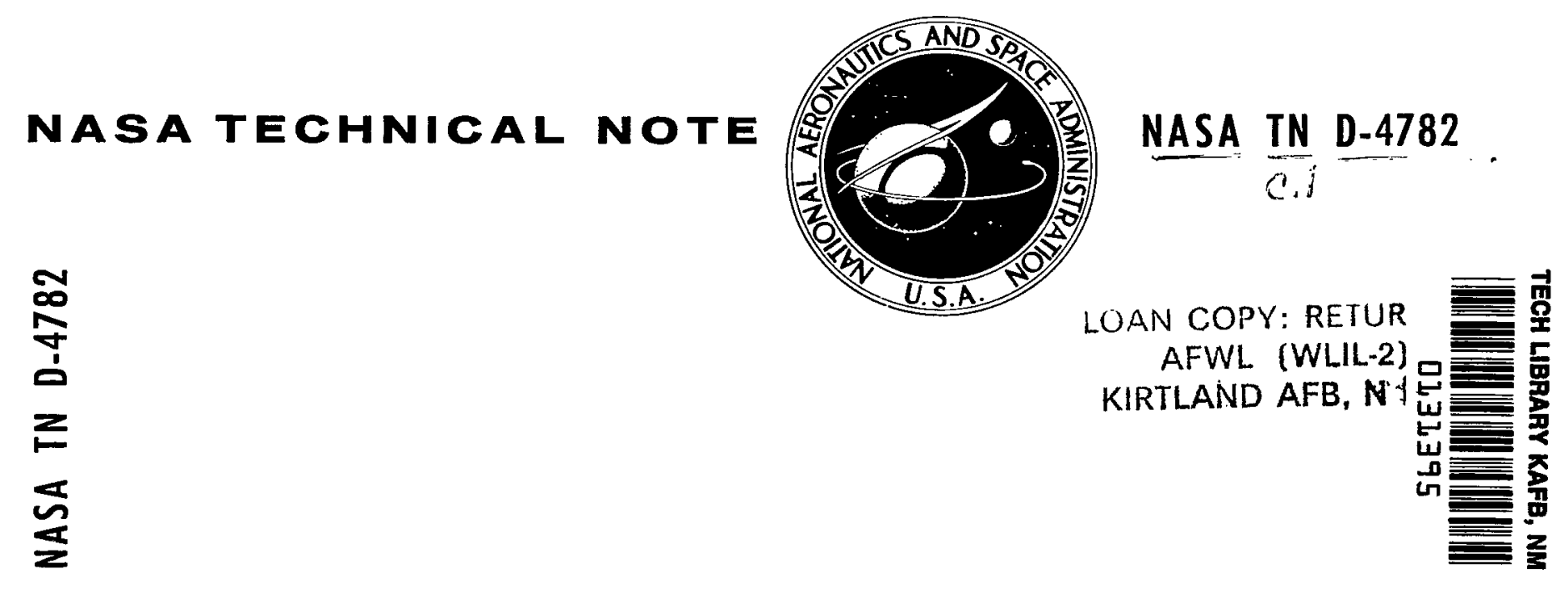

\title{
ULTRASONIC DETECTION AND MEASUREMENT OF FATIGUE CRACKS IN NOTCHED SPECIMENS
}

by Stanley J. Klima and Jobn C. Freche

Lewis Research Center

Cleveland, Obio

NATIONAL AERONAUTICS AND SPACE ADMINISTRATION - WASHINGTON, D. C. - SEPTEMBER 1968 


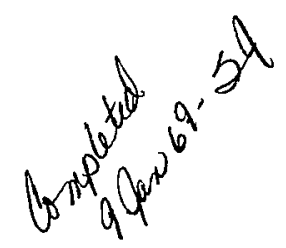

ERRATA

NASA Technical Note D-4782

ULTRASONIC DETECTION AND MEASUREMENT OF

FATIGUE CRACKS IN NOTCHED SPECIMENS

by Stanley J. Klima and John C. Freche

September 1968

Page 4, figure 2: The value for radius in millimeters should be 0.250 instead of 0.025 .

Pages 16 and 17, figure 5: The values for crack depth in millimeters in the curve labels should read as follows: $5(\mathrm{a}), 0.028$ to $0.051 ; 5(\mathrm{~b}), 0.013$ to $0.104 ; 5(\mathrm{c}), 0.025$ to $0.064 ; 5(\mathrm{~d}), 0.66$ to $0.107 ; 5(\mathrm{e}), 0.036$ to 0.102 .

Page 16, figure 5(c): The values for crack depth in millimeters in the key should read $0.28, .51, .66$. 


\title{
ULTRASONIC DETECTION AND MEASUREMENT OF FATIGUE CRACKS IN NOTCHED SPECIMENS
}

\author{
By Stanley J. Klima and John C. Freche. \\ Lewis Research Center \\ Cleveland, Ohio
}

\section{NATIONAL AERONAUTICS AND SPACE ADMHAISTRATION}




\section{ABSTRACT}

An ultrasonic technique was developed and used to observe the formation and growth of fatigue cracks in notched cylindrical specimens subjected to reversed axial fatigue loading. Fatigue curves showing cycles to initially detectable cracks as well as cycles to fracture were obtained for an aluminum-, a titanium-, and a cobalt-base alloy and for a maraging steel. Depth of initially detectable cracks ranged between approximately 0.0005 and 0.004 in. $(0.013$ and $0.10 \mathrm{~mm})$. Also obtained were curves relating ultrasonic system output voltage to crack depths up to 0.030 in. $(0.76 \mathrm{~mm})$ for three materials. These curves were used to demonstrate the capability of the device for monitoring crack growth. 


\title{
ULTRASONIC DETECTION AND MEASUREMENT OF FATIGUE CRACKS IN NOTCHED SPECIMENS*
}

\author{
by Stanley J. Klima and John C. Freche \\ Lewis Research Center
}

\section{SUMMARY}

An ultrasonic technique was developed and used to observe the formation and growth of fatigue cracks in notched cylindrical specimens subjected to reversed axial fatigue loading. Fatigue curves showing cycles to initially detectable cracks as well as cycles to fracture were obtained for an aluminum-, a titanium-, and a cobalt-base alloy and for a maraging steel. Curves relating system output voltage to crack depths up to about 0.030 inch $(0.76 \mathrm{~mm})$ were also obtained for three of the materials. The latter curves were used to demonstrate the capability of the device for monitoring fatigue crack growth.

The reflection method was used while the test was in progress to detect initial fatigue cracks, which ranged in depth from approximately 0.0005 to 0.004 inch $(0.013$ and $0.10 \mathrm{~mm}$ ) for the materials used. The cracks generally extended around the entire specimen circumference and were formed within approximately 10 to 40 percent of life to fracture, depending on material and cyclic stress. Curves of system output voltage versus crack depth for a given material were virtually the same regardless of cyclic stress level, but were different for different materials.

Fatigue cracks were generally transgranular for all materials. At stresses well above the fatigue limit, the fatigue macrocrack front advanced uniformly around the specimen circumference until a point of rapidly accelerated crack growth was reached. At lower stresses, near the fatigue limit of the notched specimen, the crack that caused fracture usually propagated from one side of the specimen.

* To be presented in part at SESA Fall Meeting, San Francisco, Calif., Oct. 28Nov. 1, 1968. 


\section{INTRODUCTION}

Fatigue involves the processes of crack initiation and propagation prior to fracture. Any method that can be used to detect small fatigue cracks nondestructively during the course of a fatigue test would be extremely useful as a research test tool. If the method could also be used to monitor fatigue crack growth, its usefulness would be even greater.

Methods for the detection of fatigue cracks are presently available. Generally, however, the use of each presents associated difficulties that are more or less severe, depending on the intended application. For example, when commonly used inspection methods, such as penetrating-liquid, magnetic-particle, and radiographic techniques, are applied to fatigue specimens, all require interruption of the fatigue test. Additional limitations are that the penetrating-liquid and magnetic-particle techniques can only be used to detect cracks at or near the surface and that X-ray techniques pose problems of safety and interpretation. Optical microscopy is probably the most positive means of measuring the size of fatigue cracks, but this method requires highly polished surfaces and generally involves terminating the test and sectioning the specimen before examination. A recent preliminary investigation (ref. 1) utilized microwave methods to detect machined grooves approximately 0.0001 inch $(0.0025 \mathrm{~mm})$ deep and 0.8 inch $(20.3 \mathrm{~mm})$ long in the surface of an untested specimen. The investigators predicted that further development of the technique should permit the detection of even smaller cracks; however, they did not demonstrate the applicability of the technique to specimens while they were undergoing a fatigue test.

In order to detect fatigue cracks in a variety of materials accurately and without interruption of the fatigue test, an ultrasonic method was applied in a previous investigation (ref. 2) for the early detection of fatigue cracks in center-notched sheet specimens. In that initial investigation, the reflection technique was used, and fatigue cracks ranging in length from 0.0005 to 0.005 inch $(0.013$ to $0.13 \mathrm{~mm})$ were detected while the tests were in progress. Another investigator (ref. 3) used ultrasonic surface waves to detect surface flaws in bending fatigue specimens, but crack sizes were not determined. Still others (ref. 4) have applied ultrasonic inspection techniques to detect cracks 0.003 to 0.004 inch $(0.08$ to $0.10 \mathrm{~mm})$ long in thin $(0.039 \mathrm{in}$.) $(1.0 \mathrm{~mm})$ center-notched steel sheet specimens that were tested in axial fatigue.

The earlier investigation (ref. 2) was limited to axial tension fatigue tests of sheet specimens, and the transducer design was therefore tailored for application to sheet specimens. In the present investigation, the transducer design was altered to permit application of the ultrasonic method to cylindrical (notched) specimens subjected to reversed axial fatigue loading. The reflection technique was employed during the test to detect fatigue cracks in 2014-T6 aluminum, 5 aluminum(Al)-2. 5 tin (Sn)-titanium (Ti), a 300 grade maraging steel, and a cobalt-base alloy L-605. Fatigue curves were obtained 
showing cycles to initially detectable cracks and cycles to fracture. Some specimens were removed from test, sectioned, and examined optically to relate crack length to system output voltage. The device was calibrated in terms of output voltage as a function of crack depth for three materials over a range of stresses.

\section{PRINCIPLES OF CRACK DETECTION BY ULTRASONIC REFLECTION TECHNIQUE}

The principles of ultrasonic wave propagation are described in detail in references 5 to 7 . This section briefly reviews the theory involved in applying the reflection technique to the detection of fatigue cracks. The technique is similar to the use of radar in the detection of distant objects. Acoustic energy, in the form of high-frequency waves, is transmitted from a transducer into the test specimen. After transmission of each pulse of energy, the transducer acts as a receiver for energy reflected from any discontinuity in the specimen. The metal-air interface of a fatigue crack constitutes such a discontinuity. The low density of air and the relatively low velocity of ultrasonic waves in air result in an acoustic mismatch that causes the reflection of incident ultrasonic waves. The amount of energy reflected from a crack is directly related to the crack area, the intensity of the incident ultrasonic wave, and the orientation of the crack. In this report, crack size is discussed in terms of the average depth of penetration around the entire circumference of the notched cylindrical specimen.

\section{SYSTEM DESIGN AND OPERATION}

A block diagram of the ultrasonic crack-detection system is shown in figure 1 . A

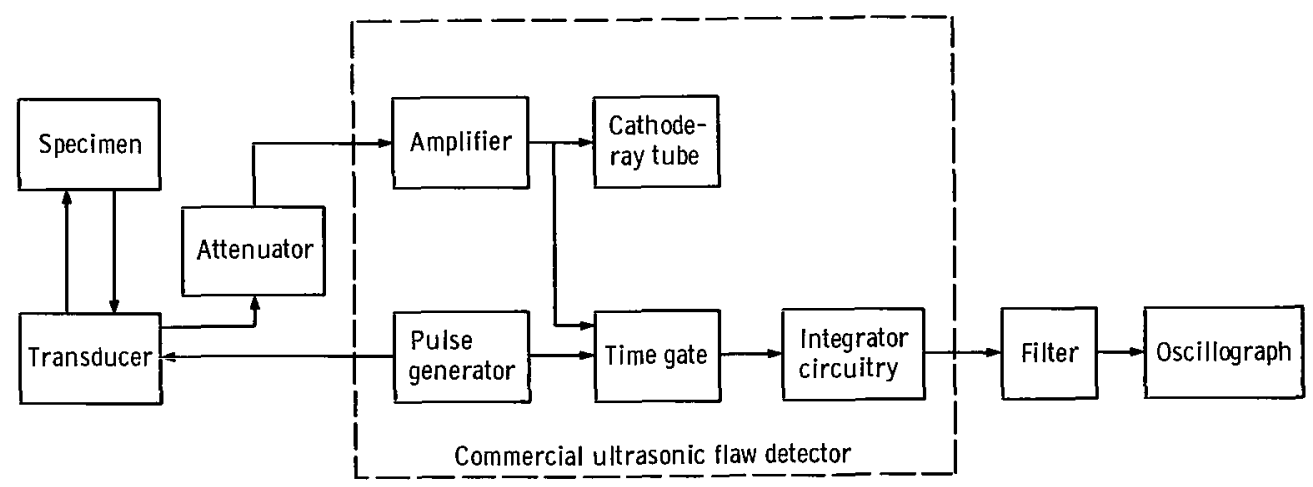

Figure 1. - Crack-detection system. 
commercial ultrasonic flaw detector was used in this investigation. This unit contained a pulse generator used to drive the piezoelectric crystal in the transducer. It also contained amplifiers and a cathode-ray tube that displayed the reflected energy pattern, as well as a time gate and integrator circuitry. Filter circuitry and an oscillograph were added. The oscillograph was used to obtain a permanent record of the signal reflected from the notch and the propagating crack in the specimen.

\section{Specimen-Transducer Design and Assembly}

A sketch of the notched cylindrical fatigue specimen used in this investigation is shown in figure 2, and figure 3 shows the specimen, transducer, and loading rod assembly.

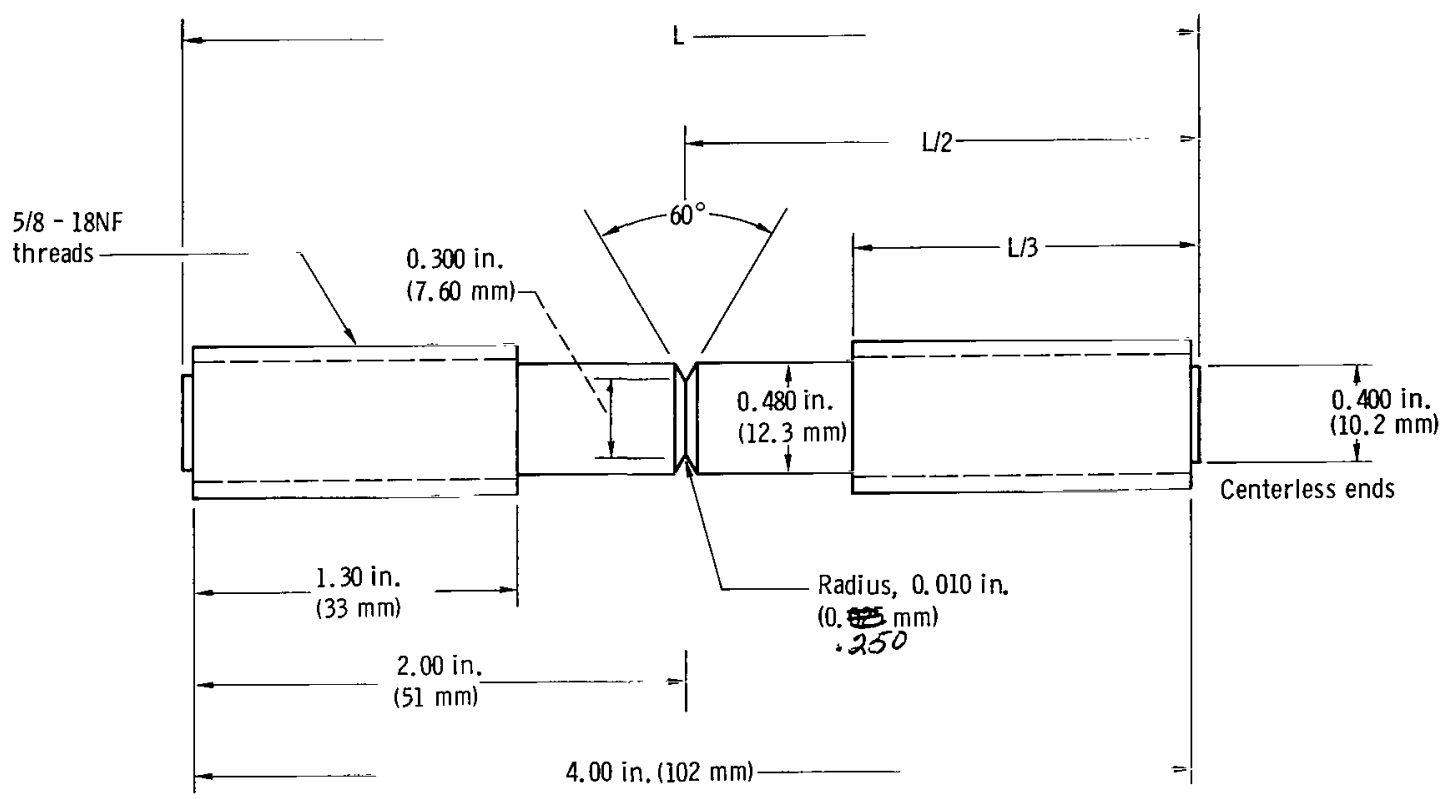

Figure 2. - Notched cylindrical fatigue specimen. Theoretical stress concentration, 3.65.

Longitudinal ultrasonic waves were transmitted to the specimen by a transducer mounted on the specimen end. Access to the specimen end, after its installation in the fatigue machine, was achieved through an opening in the upper loading rod (fig. 3). The transducer was clamped in position by a yoke that screwed onto the end of the specimen and was large enough to accommodate a $1 / 2$-inch- (13-mm-) diameter, 3/8-inch- (10-mm-) thick transducer. 


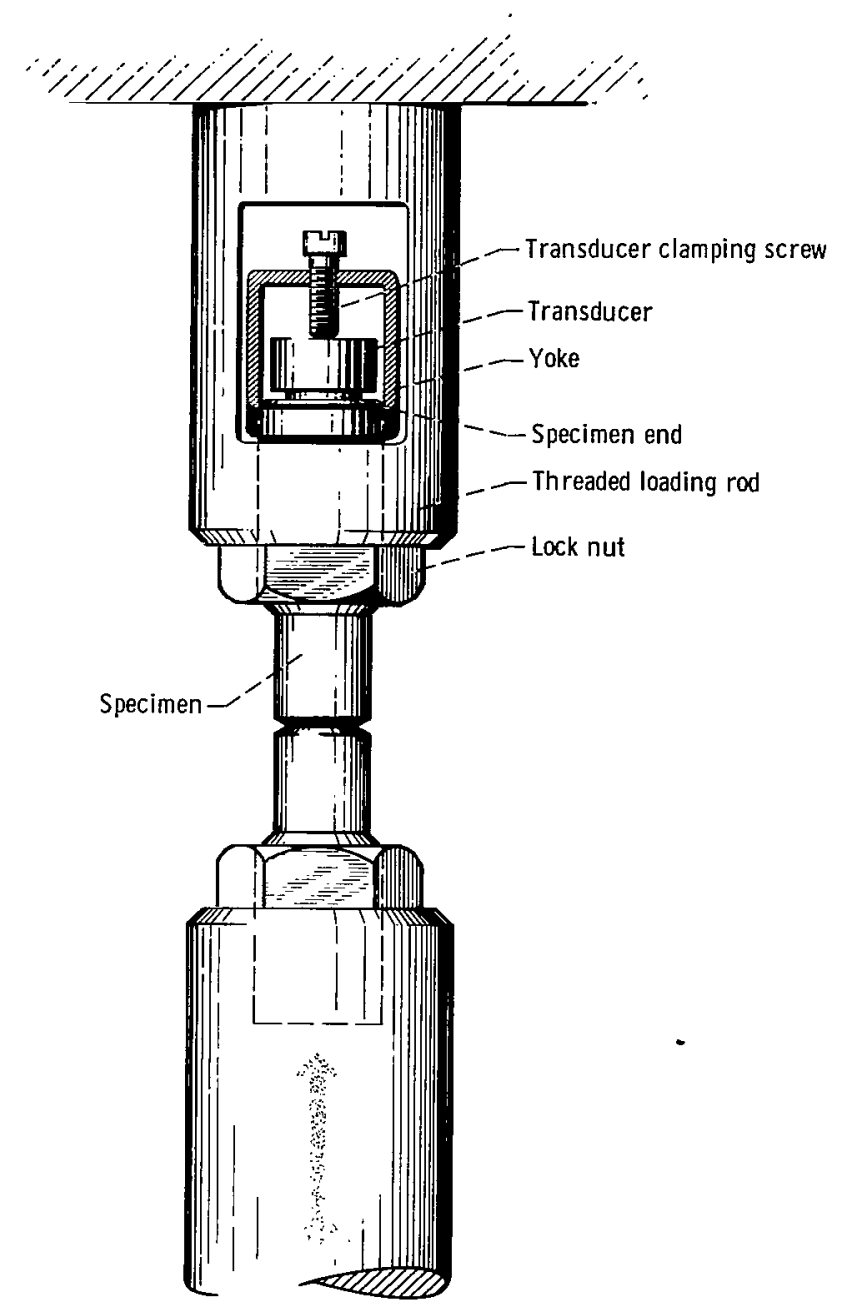

Figure 3. - Fatigue specimen, transducer, and loading rod assembly.

The specimen was machined so that a 0.4 -inch- (10-mm-) diameter section extended beyond the threaded portions (fig. 2). Because the transducer was clamped against this extension, which had a diameter less than the root diameter of the threads, the amount of stray ultrasonic waves that would ordinarily reach the transducer from reflective surfaces on the threads was reduced. No fillet was provided between the test section and the threads so that reflected waves from the specimen shoulder could return directly to the transducer and be displayed on the cathode-ray tube as a distinct spike. A generous fillet in this region apparently caused the reflected waves from the fillet to travel a longer, more indirect route. Therefore, they arrived at the transducer at about the same time as the reflected signal from the specimen notch, which caused a superposition of the signals that is undesirable because it tends to mask the reflected signal 
from the specimen notch. For the same reason it was necessary to position the specimen notch so that its distance from the transducer was not a multiple of the distance between any other strongly reflective surface and the transducer. Thus, secondary reflections caused by waves bouncing back and forth between the end of the specimen adjacent to the transducer and discontinuities such as the shoulder were not superimposed on the signal from the notch.

A coupling medium between the transducer and the fatigue specimen was provided to eliminate air from the interface and to allow the efficient transmission of ultrasonic energy. A mineral oil-calcium soap grease was used, but a wide choice of petroleum or silicone lubricants would probably be satisfactory. The specimen ends were polished with 600 grit abrasive paper to obtain a smooth flat surface and ensure a good fit between the transducer and the specimen.

\section{Transducer Characteristics}

A transducer frequency of 7.0 megahertz was chosen for this investigation. Theoretically, higher frequency transducers, because of their associated short wavelength, are sensitive to smaller flaws than are low-frequency (long wavelength) transducers. However, energy losses by attenuation are greater with short wavelengths than with long wavelengths. Therefore, a desirable compromise is to choose as high a frequency as possible without incurring excessive attenuation losses. Generally, this choice must be made experimentally.

Determination of the optimum frequency for a particular application can be hampered by apparent differences in energy levels produced by different transducers. In this investigation, for example, pairs of 7.0-megahertz transducers were purchased from the same manufacturer on three different occasions (a pair at a time). Each pair provided a different level of reflected energy from the notch of the fatigue specimen. The pair that was the most sensitive in obtaining reflections from the specimen notch was used for the tests. A pair of 10.0-megahertz transducers purchased from the same supplier had approximately the same sensitivity as the least sensitive pair of 7.0-megahertz transducers. This difference points out a difficulty likely to be encountered by investigators while selecting the proper transducer for a particular experiment.

\section{Operation of System Electronics}

Ultrasonic pulses were transmitted at the rate of 500 per second with a pulse time of about 1 microsecond. Because a typical velocity for longitudinal waves in the specimens 
used in this investigation was about 0.2 inch $(5 \mathrm{~mm})$ per microsecond, sufficient time was available between pulses for all reflected signals to return to the drive crystal. These reflected pulses were reconverted to electrical signals by the transducer, amplified, and displayed on the cathode-ray tube.

The commercial ultrasonic equipment included a time gate and an integrator circuit (fig. 1). The gate allowed only the reflected signals occurring within a preselected time interval after each transmitted pulse to pass through to the integrator circuitry. Because the distance traveled by an ultrasonic pulse is proportional to time, the time gate may be interpreted as a "propagation-distance" gate. The output of the amplifier was gated for the specimen position at which fatigue cracking was expected to occur. Extraneous reflections from the specimen-transducer interface and from within the specimen were blocked by this gate.

The integrator circuitry provided a dc voltage proportional to the signal that passed through the time gate. After minor fluctuations in the integrator output were removed by the filter, the resulting dc voltage was recorded on an oscillograph. Changes in the recorded voltages were proportional to changes in the amount of ultrasonic energy received.

\section{MATERIALS AND FATIGUE-TEST PROCEDURE}

\section{Specimen Materials}

Specimens (fig. 2) were machined from 3/4-inch- (19-mm-) bar stock of four alloys - 2014-T6 aluminum, 5 aluminum (Al)-2. 5 tin ( $\mathrm{Sn}$ )-titanium ( $\mathrm{Ti}$ ), a maraging steel, and a cobalt-base alloy, L-605. The nominal composition of the alloys is given in table I. The condition of these materials and their tensile strengths obtained with the specimens used in this investigation are listed in table II. All test specimens contained a circumferential notch having a theoretical stress concentration $K_{t}$ of 3.65 (ref. 8). The root of the notch was polished with a rotating 10-mil-diameter wire impregnated with abrasive to remove circumferential machining marks. Stress values were calculated on the basis of the minimum cross-sectional area bounded by the notch root. The maraging steel was tested in both the aged and the as-received conditions to determine the difference in response of the ultrasonic method to a material with the same composition but with different mechanical properties. 
TABLE I. - NOMINAL COMPOSITION OF ALLOYS TESTED

\begin{tabular}{|c|c|c|c|c|}
\hline \multirow[t]{3}{*}{ Element } & \multicolumn{4}{|c|}{ Alloy } \\
\hline & 2014-T6 & 5Al-2.5Sn-Ti (ELI) ${ }^{\mathrm{a}}$ & $\begin{array}{c}300 \text { Grade } \\
\text { maraging steel }\end{array}$ & L-605 \\
\hline & \multicolumn{4}{|c|}{ Composition, wt. \% } \\
\hline Aluminum & Balance & 5.2 & 0.10 & ------ \\
\hline Calcium & -....- & ----- & .05 & ----- \\
\hline Carbon & ----- & $\mathrm{b}_{0.08}$ & ${ }^{b} .03$ & 0.10 \\
\hline Chromium & $\mathrm{b}_{0.10}$ & $-\ldots-\cdots$ & ----- & 20.0 \\
\hline Cobalt & $-\ldots$ & -- & 9.00 & Balance \\
\hline Copper & 4.4 & 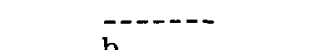 & ----- & - \\
\hline Iron & $b_{1.00}$ & ${ }^{b} 0.15$ & Balance & $\mathrm{b}_{3.00}$ \\
\hline Magnesium & .5 & $---1-$ & ----- & --- \\
\hline Manganese & .8 & $----n$ & ${ }^{b} 0.10$ & 1.5 \\
\hline Molybdenum & ----- & $-\cdots--$ & 4.80 & $---\cdots$ \\
\hline Nickel & ----- & ------ & 18.50 & 10.0 \\
\hline Silicon & 0.8 & $-\cdots--$ & b. 10 & $\mathrm{~b}_{1.00}$ \\
\hline Tin & 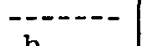 & 2.5 & ----- & $-\cdots$ \\
\hline Titanium & $b_{0.15}$ & Balance & 0.60 & $-\cdots-$ \\
\hline Tungsten & ----- & $-\cdots--$ & $---\cdots$ & 15.0 \\
\hline Zirconium & $\cdots \cdots$ & $-\cdots-$ & 0.02 & $-\cdots$ \\
\hline Zinc & $\mathrm{b}_{0.25}$ & ---- & $-\cdots--$ & ---- \\
\hline Boron & $-\cdots--$ & $-\cdots--\infty$ & 0.003 & - \\
\hline Sulfur & ---- & $--\cdots$ & b. 010 & $\mathrm{~b}_{0.030}$ \\
\hline Phosphorus & ----- & $-\cdots-$ & ${ }^{b} .010$ & b. 040 \\
\hline Oxygen & -...... & $\mathrm{b}_{0.12}$ & $\ldots$ & $-\cdots$ \\
\hline Hydrogen & $-\cdots--$ & ${ }^{\mathrm{D}} .0125$ & $-\cdots--$ & |------ \\
\hline Nitrogen & $-\cdots--$ & .05 & $-\cdots-$ & --- - \\
\hline
\end{tabular}


TABLE II. - TENSILE STRENGTH AND CONDITION OF ALLOYS TESTED

\begin{tabular}{|c|c|c|c|}
\hline \multirow[t]{2}{*}{ Material } & \multirow[t]{2}{*}{ Condition } & \multicolumn{2}{|c|}{$\begin{array}{l}\text { Tensile strength } \\
\text { of notched } \\
\text { specimens }\end{array}$} \\
\hline & & psi & $\mathrm{MN} / \mathrm{m}^{2}$ \\
\hline $\begin{array}{l}\text { 2014-T6 } \\
\text { Aluminum }\end{array}$ & T6 (artificially aged) & 97400 & 672 \\
\hline $\begin{array}{l}\text { 5Al-2.5Sn-Ti } \\
\text { (ELI) }\end{array}$ & $\begin{array}{l}\text { Annealed (as-received); Rockwell-C } \\
\text { hardness, } 30 \text { to } 33\end{array}$ & 213400 & 1471 \\
\hline Maraging steel & $\begin{array}{l}\text { Solution annealed at } 1500^{\circ} \mathrm{F}(1088 \mathrm{~K}) \\
\text { for } 3 / 4 \mathrm{hr} \text { and air cooled; aged at } \\
900^{\circ} \mathrm{F}(756 \mathrm{~K}) \text { for } 3 \mathrm{hr} \text { and air } \\
\text { cooled }\end{array}$ & 413700 & 2852 \\
\hline Maraging steel & $\begin{array}{l}\text { Solution annealed at } 1500^{\circ} \mathrm{F}(1088 \mathrm{~K}) \\
\text { for } 3 / 4 \mathrm{hr} \text { and air cooled (as- } \\
\text { received) }\end{array}$ & 253500 & 1748 \\
\hline $\begin{array}{l}\text { Cobalt-base } \\
\text { alloy } \mathbf{L}-605\end{array}$ & Solution treated (as-received) & 166500 & 1148 \\
\hline
\end{tabular}

\section{Fatigue Tests}

Specimens were placed in a hydraulically actuated axial fatigue machine and subjected to reversed loading applied in a sinusodial pattern. The frequency of the load application varied between 0.3 and 1.2 hertz, depending on the expected fatigue life to fracture. All tests were conducted in air at ambient temperatures.

\section{Detection of Initial Cracks by Ultrasonic Method}

The depth of cracks initially detectable by the ultrasonic reflection technique was less than 0.005 inch $(0.13 \mathrm{~mm})$ for all the materials considered. The transducer was positioned at one end of the specimen, and longitudinal waves traveled along the entire specimen length. The reflections of these waves from the notch were observed as a spike on the cathode-ray tube. The same reflected signal, after passing through the time gate, was also recorded on an oscillograph (fig. 1). The amplifier suppression (dc bias) was adjusted to reduce the notch signal to an output level so that an oscillograph recording at the start of the test was made near the middle of the chart, which left room to record either a decreasing or an increasing signal. 


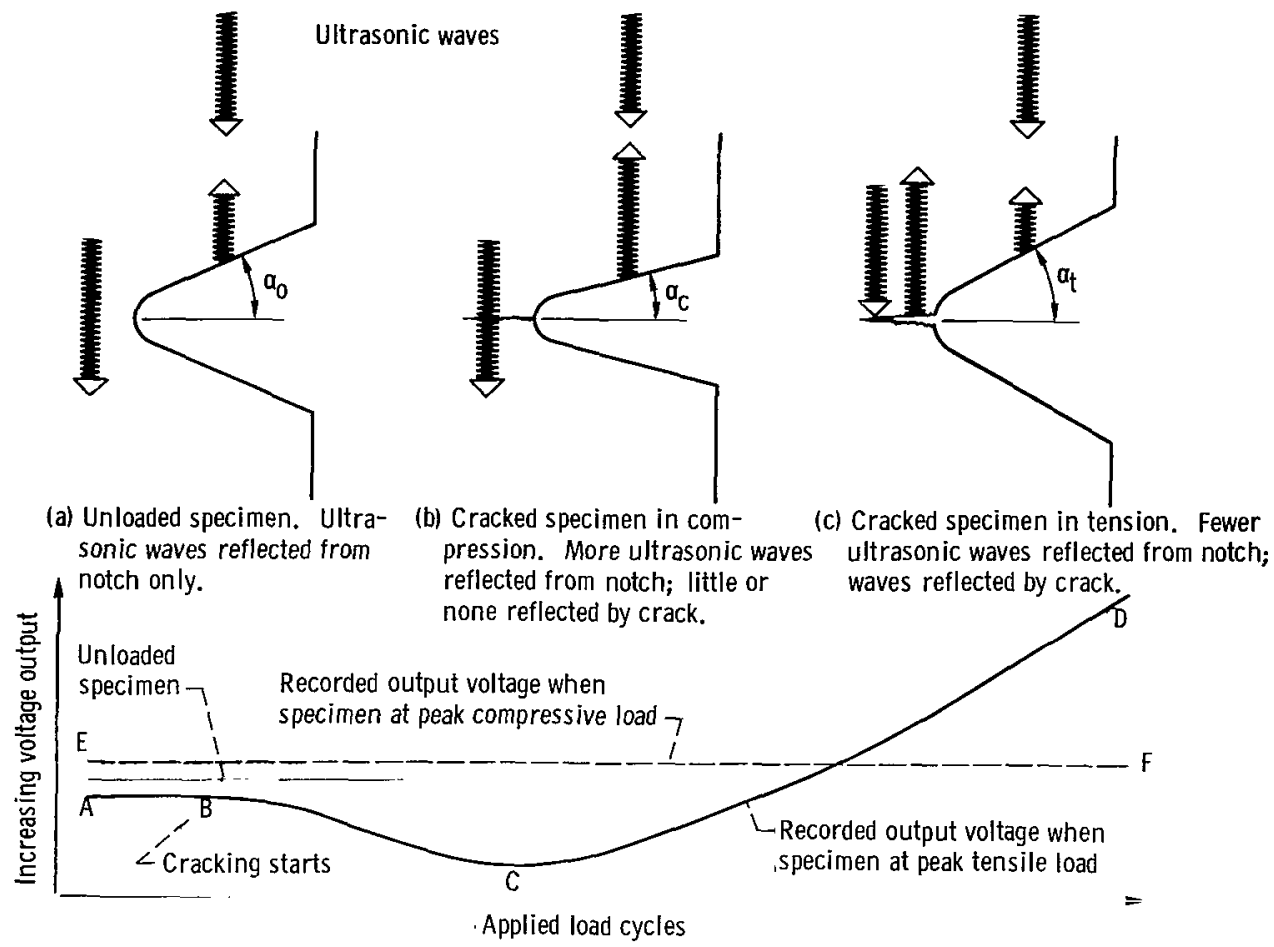

(d) Level of output voltage at peak load application.

Figure 4. - Schematic illustration of recorded output voltage and effects of cyclic loading and crack formation. $\left(a_{c}<a_{0}<a_{t}\right)$

Figure 4 schematically illustrates how the recorded output voltage was affected by an applied cyclic load as well as by crack formation and crack growth during the early part of a fatigue test of the particular specimen used in this investigation. The direction of the increasing reflected signal received by the transducer is toward the top of figure 4(d). The dashed line EF represents the level of output voltage recorded whenever the peak compressive load was applied to the specimen. The solid line ABCD represents the level of output voltage recorded whenever the peak tensile load was applied. Note that the solid line first decreases and then increases with an increasing number of applied load cycles. Because the output voltage at peak tensile load is of primary interest for the detection of cracks, this curve is discussed in detail.

A sketch of a longitudinal section in the region of the specimen notch at no-load condition prior to the fatigue test is shown in figure 4(a). The angle between the notch surface nearest the transducer and a plane perpendicular to the direction of the ultrasonic waves is designated $\alpha_{0}$. The ultrasonic waves reflected from the notch, before the load is applied, provide an output voltage level that is about midway between points $\mathrm{A}$ and $\mathrm{E}$ on the two output voltage curves. Whenever the peak compressive load is applied, the 
notch angle is reduced to $\alpha_{c}$ (fig. 4(b)). Thus, the notch surface from which the incident waves are reflected becomes more nearly perpendicular to the direction of the incident ultrasonic waves, and the result is increased reflected energy over the no-load condition. The voltage level at the peak compressive load remains constant, even when cracks first appear, because the crack surfaces are so tightly squeezed together that transmission of ultrasonic waves across the interface is permitted. When the tensile load is applied, the notch angle is increased to some value greater than $\alpha_{0}$ and the output voltage level is correspondingly reduced from the no-load condition. As long as no cracks form, the output voltage at peak tensile load remains constant, as shown in the region $A$ to $B$ (fig. 4(d)). When tiny cracks (too small to reflect a significant amount of ultrasonic energy) form in the notch root, the notch angle apparently is further increased and probably causes the level of the reflected ultrasonic energy to be progressively reduced (region from $B$ to $C$ ). The initial decrease in output voltage, point $B$, can therefore be used as an indication of initial cracking in the specimen. The voltage level used in this investigation as an indication of initial cracking was higher than point $\mathbf{C}$ but considerably lower than that of point B. Thus, by arbitrarily choosing a smaller voltage decrease it is probable that smaller cracks could be detected with this apparatus. It should be emphasized that the only requirement to establish the presence of a crack is that the decrease in output voltage from point $B$ exceed the minor fluctuations inherent in the instrumentation.

Continued crack growth results in (1) a decreased amount of reflected energy from the notch and (2) an increasing amount of reflected energy from the crack itself, and thus influences the recorded net output voltage. When point $\mathrm{C}$ is reached (fig. $4(\mathrm{~d})$ ), the crack surface area is large enough to reflect sufficient ultrasonic energy to overcome the effects of the increased angle $\alpha_{\mathrm{t}}$ (fig. $4(\mathrm{c})$ ), and the recorded output voltage increases (in a nonlinear fashion) until the specimen fractures.

\section{Measurement of Large Cracks by Ultrasonic Method}

The ultrasonic device was also used to measure cracks between 0.005 and 0.030 inch (0. 13 and $0.76 \mathrm{~mm}$ ) deep. This measurement was accomplished with only one change made in the system; an attenuation unit was inserted between the transducer and the reflected signal input to the amplifier (fig. 1). The attenuation was variable from 0 to 42 decibels, and it permitted a ratio to be obtained between any two levels of reflected ultrasonic energy from the fatigue crack. The manner of obtaining this ratio can be illustrated by using the schematic output voltage trace of figure 4(d). In any test, the value of the lowest output voltage (point $\mathrm{C}$ ) was arbitrarily designated as the reference for all subsequent output voltage readings and was given a unit designation Inserting sufficient attenuation 
brought the level of any subsequent recorded output voltage back to unity (i.e., the level recorded at point $\mathrm{C}$ ). The number of decibels required to achieve this result was noted. The ratio of output voltage to the reference voltage was determined by reference to a table provided by the manufacturer of the attenuator. Stopping the fatigue test, breaking the specimen, and then optically measuring the size of the fatigue crack corresponding to this ratio permitted the establishment of a relation between the crack depth or crack area and the normalized output voltage. When this procedure was repeated for several different crack depths and corresponding output voltage levels, a calibration curve for a given material was obtained. Such calibration curves may be used in subsequent tests of the particular material and specimen geometry to measure crack size without interruption of the fatigue test.

\section{Optical Crack Measurement for Calibration Purposes}

Upon first detection of a crack, some specimens were removed from the fatigue machine and sectioned longitudinally for microscopic examination. The sections were polished and etched to better define the crack. The image of the area containing the crack was projected on a metallograph screen at a magnification of 500 , and the crack image was measured to the nearest 0.010 inch (to the nearest $0.00002 \mathrm{in}$. or $0.0005 \mathrm{~mm}$ of actual crack depth). Four crack-depth measurements were made on each specimen at points $90^{\circ}$ apart, and the average was used.

For the measurement of deeper cracks (up to 0.030 in. or $0.16 \mathrm{~mm}$ ), specimens were first broken in tension, and the depth of the fatigue-crack portion was measured at a magnification of 10 with the use of a graduated eyepiece. The reported crack depths represent the average of 12 readings evenly spaced around the circumference of each specimen. If no crack existed at a particular measuring point, a crack length of zero was assigned to that reading so that all 12 points would be included in the calculated average depth. This procedure was rarely necessary because in most cases, the crack front progressed uniformly around the specimen circumference.

\section{RESULTS AND DISCUSSION}

\section{Fatigue Data}

The fatigue data are given in table III. Fatigue curves showing cycles to initially detectable cracks and cycles to fracture are plotted in figure 5 . The solid circles repre- 
TABLE III. - SUMMARY OF FATIGUE CRACK-DETECTION DATA

\begin{tabular}{|c|c|c|c|c|c|c|}
\hline \multicolumn{2}{|c|}{ Maximum cyclic stress } & \multirow{2}{*}{\multicolumn{2}{|c|}{$\begin{array}{l}\text { Depth of initially detectable } \\
\text { crack (optical measurement) }\end{array}$}} & \multirow{3}{*}{$\begin{array}{l}\text { Number of cycles } \\
\text { to initially } \\
\text { detectable crack, } \\
\mathrm{N}_{\mathrm{o}}\end{array}$} & \multirow{3}{*}{$\begin{array}{c}\text { Number of cycles } \\
\text { to fracture, } \\
\mathrm{N}_{\mathbf{F}}\end{array}$} & \multirow{3}{*}{$\begin{array}{l}\mathrm{N}_{\mathrm{o}} / \mathrm{N}_{\mathrm{F}}, \\
\text { percent }\end{array}$} \\
\hline \multirow{2}{*}{ $\pm p s i$} & \multirow{2}{*}{$\pm \mathrm{MN} / \mathrm{m}^{2}$} & & & & & \\
\hline & & in. & $\mathrm{mm}$ & & & \\
\hline \multicolumn{7}{|c|}{ 2014-T6 Aluminum } \\
\hline 45000 & 310 & 0.0018 & 0.046 & $\begin{array}{l}72 \\
79\end{array}$ & 404 & 19 \\
\hline 35000 & 241 & 0.0011 & 0.028 & $\begin{array}{l}229 \\
283\end{array}$ & 1599 & 16 \\
\hline 25000 & 172 & 0.0020 & 0.051 & $\begin{array}{l}785 \\
770\end{array}$ & 5475 & \} \\
\hline 15000 & 103 & 0.0011 & 0.028 & $\begin{array}{ll}11 & 125 \\
10 & 500\end{array}$ & 63529 & 17 \\
\hline \multicolumn{7}{|c|}{ 5Al-2. 5Sn-Ti } \\
\hline 100000 & 689 & $\begin{array}{r}0.0005 \\
.0011 \\
- \\
-\end{array}$ & $\begin{array}{r}0.013 \\
.028 \\
---- \\
----\end{array}$ & $\begin{array}{l}50 \\
66 \\
54 \\
61\end{array}$ & $\begin{array}{r}316 \\
372\end{array}$ & 17 \\
\hline 80000 & 552 & $\begin{array}{r}0.0019 \\
.0012 \\
- \\
- \\
-\end{array}$ & $\begin{array}{r}0.048 \\
.030 \\
\\
\end{array}$ & $\begin{array}{l}115 \\
131 \\
130 \\
114 \\
105\end{array}$ & $\begin{array}{r}860 \\
902 \\
1065\end{array}$ & 13 \\
\hline 50000 & 414 & $\begin{array}{r}0.0012 \\
.0005 \\
- \\
- \\
-\end{array}$ & $\begin{array}{r}0.030 \\
.013 \\
- \\
- \\
- \\
-\end{array}$ & $\begin{array}{l}316 \\
723 \\
337 \\
375 \\
345 \\
875\end{array}$ & $\begin{array}{l}2843 \\
2957 \\
3185 \\
4 \quad 719\end{array}$ & 14 \\
\hline 40000 & 276 & $\begin{array}{r}0.0019 \\
.0041 \\
- \\
-\end{array}$ & $\begin{array}{r}0.048 \\
.104 \\
- \\
- \\
----\end{array}$ & $\begin{array}{l}2275 \\
2950 \\
1910 \\
1500\end{array}$ & 14469 & 13 \\
\hline
\end{tabular}


TABLE III. - Continued. SUMMARY OF FATIGUE CRACK-DETECTION DATA

\begin{tabular}{|c|c|c|c|c|c|c|}
\hline \multicolumn{2}{|c|}{ Maximum cyclic stress } & \multirow{2}{*}{\multicolumn{2}{|c|}{$\begin{array}{l}\text { Depth of initially detectable } \\
\text { crack (optical measurement) }\end{array}$}} & \multirow{3}{*}{$\mid \begin{array}{c}\text { Number of cycles } \\
\text { to initially } \\
\text { detectable crack, } \\
\mathrm{N}_{\mathrm{o}}\end{array}$} & \multirow{3}{*}{$\begin{array}{l}\text { Number of cycles } \\
\text { to fracture, } \\
\mathrm{N}_{\mathrm{F}}\end{array}$} & \multirow{3}{*}{$\begin{array}{l}N_{o} / N_{F} \\
\text { percent }\end{array}$} \\
\hline \multirow{2}{*}{ $\pm p s i$} & \multirow{2}{*}{$\pm \mathrm{MN} / \mathrm{m}^{2}$} & & & & & \\
\hline & & in. & $\mathrm{mm}$ & & & \\
\hline \multicolumn{7}{|c|}{ Maraging steel (heat treated) } \\
\hline \multirow[t]{3}{*}{150000} & \multirow[t]{3}{*}{1034} & 0.0012 & 0.030 & 67 & ----- & \\
\hline & & ----- & $-\cdots--$ & 81 & ------ & 11 \\
\hline & & $-\cdots$ & ---- & 67 & 640 & \\
\hline \multirow[t]{3}{*}{125000} & \multirow[t]{3}{*}{862} & 0.0018 & 0.046 & 141 & ----- & \\
\hline & & .0011 & .028 & 150 & ----- & 12 \\
\hline & & $-\cdots--$ & ----- & 157 & 1204 & \\
\hline \multirow[t]{4}{*}{100000} & \multirow[t]{4}{*}{689} & 0.0009 & 0.023 & 336 & ----- & \\
\hline & & .0011 & .028 & 378 & ----- & \\
\hline & & $-\cdots-$ & --- & 360 & 2382 & 14 \\
\hline & & ----- & ----- & 310 & 2450 & \\
\hline \multirow[t]{4}{*}{75000} & \multirow[t]{4}{*}{517} & 0.0018 & 0.046 & 1103 & ---- & \\
\hline & & .0013 & .033 & 1176 & ---- & 19 \\
\hline & & $-\cdots-\cdots$ & $\cdots-$ & 800 & 5165 & \\
\hline & & - - & ---- & 1050 & 5914 & \\
\hline \multirow[t]{4}{*}{50000} & \multirow[t]{4}{*}{345} & 0.0025 & 0.064 & 12962 & ----- & \multirow{4}{*}{41} \\
\hline & & - - - - & ---- & 13500 & 29914 & \\
\hline & & $-\cdots--$ & ---- & ----- & 34060 & \\
\hline & & ----- & ---- & $-\cdots--$ & 37500 & \\
\hline \multicolumn{7}{|c|}{ Maraging steel (as-received) } \\
\hline \multirow[t]{3}{*}{110000} & \multirow[t]{3}{*}{758} & 0.0042 & 0.107 & 94 & ----- & \multirow{3}{*}{9} \\
\hline & & ----- & ---- & 80 & 911 & \\
\hline & & $--\cdots--$ & $-\cdots-$ & 80 & 913 & \\
\hline \multirow[t]{3}{*}{90000} & \multirow[t]{3}{*}{621} & 0.0031 & 0.079 & 182 & ----- & \multirow{3}{*}{13} \\
\hline & & $--\cdots--$ & ---- & 210 & 1477 & \\
\hline & & $-\infty---$ & ---- & 260 & 1840 & \\
\hline \multirow[t]{3}{*}{70000} & 483 & 0.0030 & 0.076 & 488 & ----- & \\
\hline & & $---n-$ & ---- & 400 & 4380 & 11 \\
\hline & & ---- & ---- & 500 & 4410 & \\
\hline 50000 & 345 & 0.0026 & 0.066 & 1800 & ----- & \\
\hline & & $--\cdots-$ & ---- & 1400 & 12800 & 12 \\
\hline & $-\quad--$ & $-\cdots--$ & $-\cdots-$ & 1630 & 13500 & \\
\hline 40000 & 276 & 0.0032 & 0.081 & 6900 & --.-- & \\
\hline & & ----- & ---- & 12000 & 34270 & I 50 \\
\hline
\end{tabular}


TABLE III. - Concluded. SUMMARY OF FATIGUE CRACK-DETECTION DATA

\begin{tabular}{|c|c|c|c|c|c|c|}
\hline \multicolumn{2}{|c|}{ Maximum cyclic stress } & \multirow{2}{*}{\multicolumn{2}{|c|}{$\begin{array}{l}\text { Depth of initially detectable } \\
\text { crack (optical measurement) }\end{array}$}} & \multirow{3}{*}{$\begin{array}{l}\text { Number of cycles } \\
\text { to initially } \\
\text { detectable crack, } \\
N_{0}\end{array}$} & \multirow{3}{*}{$\begin{array}{c}\text { Number of cycles } \\
\text { to fracture, } \\
\mathrm{N}_{\mathrm{F}}\end{array}$} & \multirow{3}{*}{$\begin{array}{l}\mathrm{N}_{\mathrm{o}} / \mathrm{N}_{\mathrm{F}}, \\
\text { percent }\end{array}$} \\
\hline \multirow{2}{*}{$\pm \mathrm{psi}$} & \multirow{2}{*}{$\pm \mathrm{MN} / \mathrm{m}^{2}$} & & & & & \\
\hline & & in. & $\mathrm{mm}$ & & & \\
\hline \multicolumn{7}{|c|}{ L-605 Cobalt-base alloy } \\
\hline 120000 & 827 & 0.0040 & 0.102 & $\begin{array}{r}173 \\
187 \\
190 \\
- \\
- \\
-\end{array}$ & $\begin{array}{r}431 \\
461 \\
480\end{array}$ & 40 \\
\hline 100000 & 689 & o. 0020 & $\begin{array}{l}---- \\
---- \\
0.051 \\
----- \\
-----\end{array}$ & $\begin{array}{r}530 \\
573 \\
610 \\
--- \\
----\end{array}$ & $\begin{array}{r}---- \\
-1594 \\
11651\end{array}$ & 35 \\
\hline 80000 & 552 & 0.0025 & 0.064 & $\begin{array}{ll}1 & 500 \\
1 & 800 \\
1 & 750\end{array}$ & $\begin{array}{r}7150 \\
7940\end{array}$ & 22 \\
\hline 78800 & 543 & 0.0020 & 0.051 & 1634 & ----- & ---- \\
\hline 60000 & 414 & $\begin{array}{r}0.0014 \\
.0042 \\
0.0-\end{array}$ & $\begin{array}{r}0.036 \\
.107 \\
---- \\
---.-\end{array}$ & $\begin{array}{r}4841 \\
6273 \\
---- \\
4000\end{array}$ & $\begin{array}{ll}--1-- \\
25 & 107 \\
35 & 337\end{array}$ & 17 \\
\hline 40000 & 276 & ----- & ---- & 57000 & 442000 & 13 \\
\hline
\end{tabular}

sent those tests that were stopped upon the initial detection of a crack. The specimens were then sectioned so that the crack depths could be measured as previously described. The figure indicates the range of crack depths observed in these specimens for each material. These crack depths do not necessarily represent the smallest cracks that could be detected with this device. Rather, these crack depths correspond to an arbitrary output voltage change that was selected early in the investigation as being indicative of the presence of a measurable crack (see the Detection of Initial Cracks by UItrasonic Method section). As more experience with system operation and data readout was gained, it became evident that smaller cracks could have been detected earlier in specimen life.

Other tests were also run to obtain fatigue life to fracture. These data are represented by the open triangles in figure 5 . The open circles represent the number of cycles to the first detectable crack, as observed with the ultrasonic device, in the specimens that were run to fracture. For the particular specimen configuration used, cracks were detected 


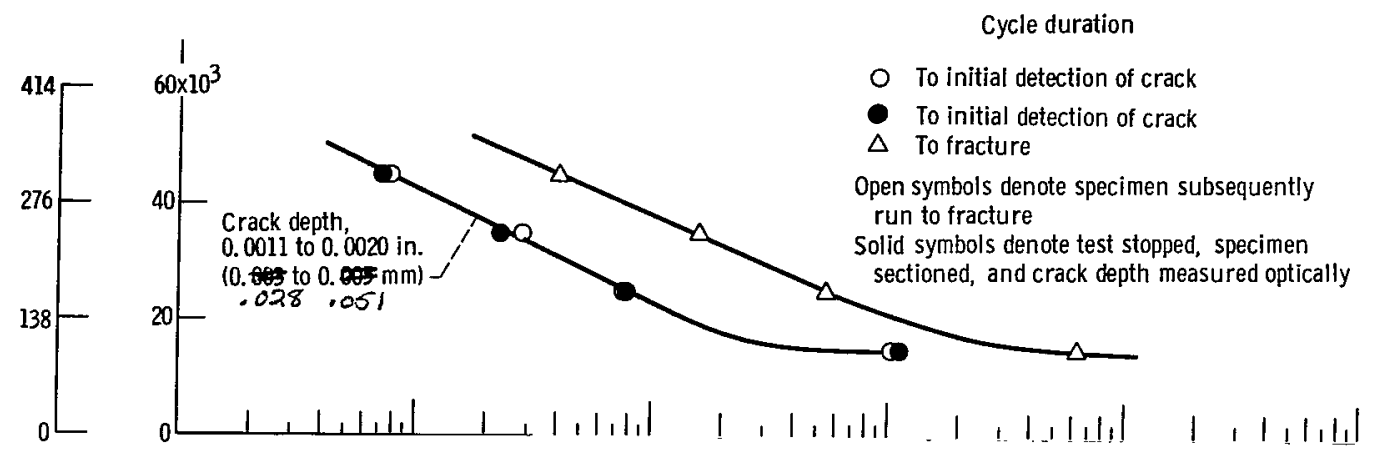

(a) 2014-T6 Aluminum alloy.
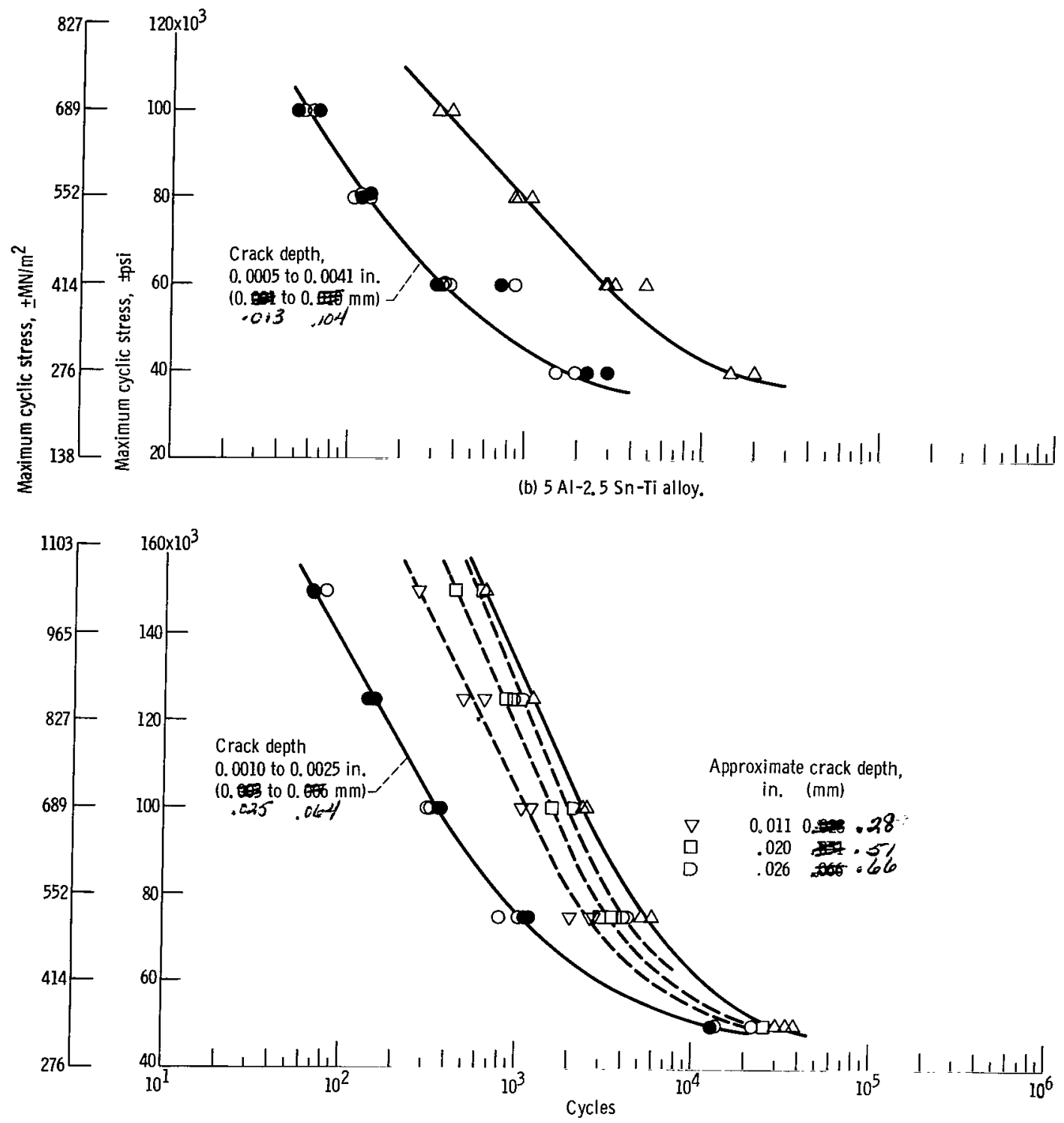

(c) Maraging steel (heat treated).

Figure 5. - Fatigue curves showing cycles to first detectable cracks and cycles to fracture for cylindrical notched specimens subjected to reversed loading. Theoretical stress concentration, 3.65. 


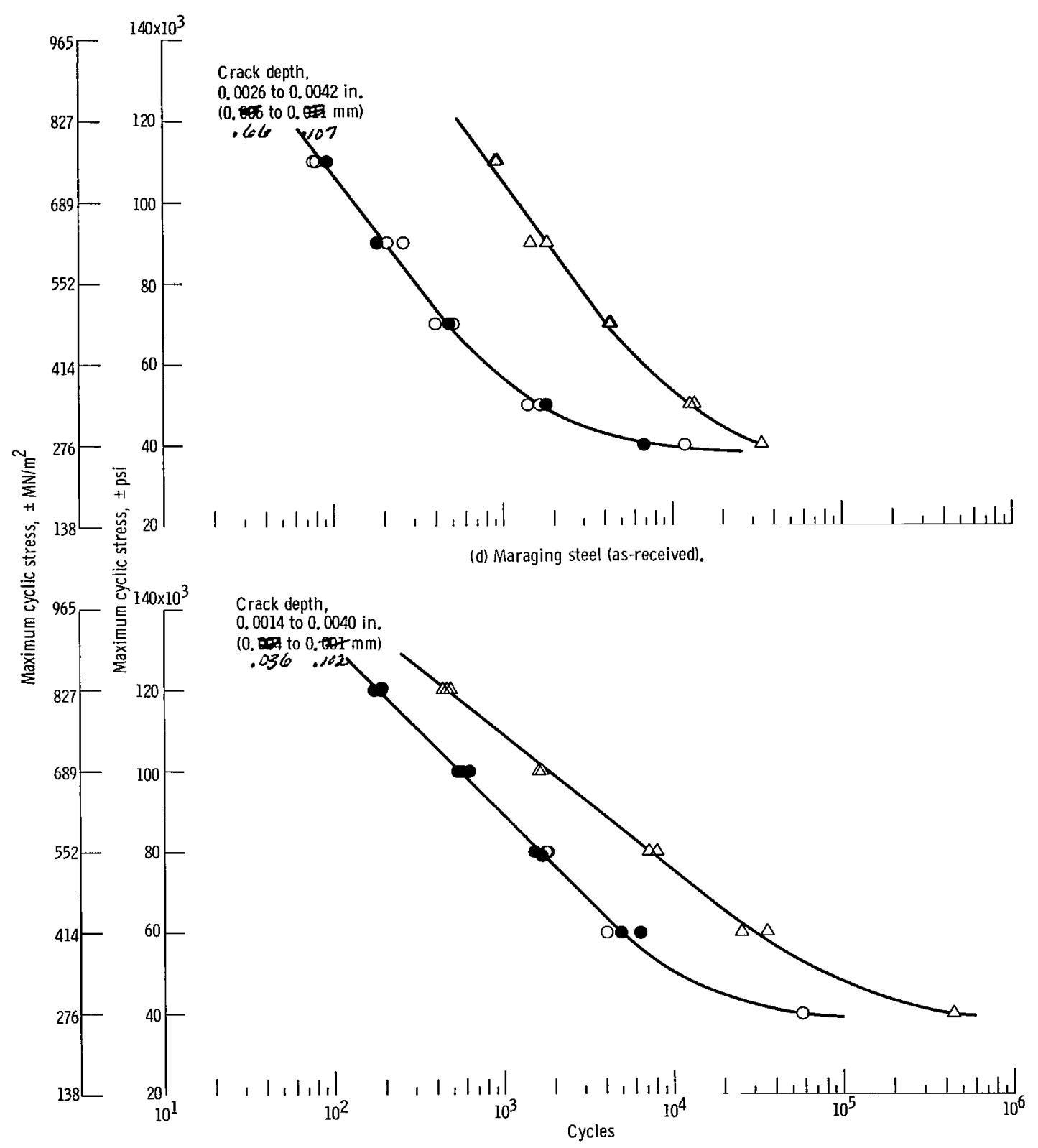

(e) Cobalt-base alloy L-605.

Figure 5. - Concluded. 
within approximately 10 to 40 percent of the life to fracture, depending on the material and the cyclic stress. The dashed curves (fig. 5(c)) represent specimen life to various crack depths, as observed by the ultrasonic method. These curves are discussed in the next section.

\section{Relation Between Output Voltage and Crack Depth}

Tests were run with three materials, and the ultrasonic method was used as a means of nondestructively measuring crack growth. A series of tests were run for each material at a relatively low stress level to obtain significantly different crack sizes. The fatigue tests were stopped, the specimens were broken in tension, and the cracks were measured optically. These crack depths were related to the output voltage observed at the time each test was terminated. A second series of specimens run at a high stress level was removed from the test when similar output voltages were observed and the crack depths measured. The details of the experimental techniques employed were described in the section Measurement of Large Cracks by Ultrasonic Method. The results of these tests are shown in figure 6 for 2014-T6 aluminum, 5Al-2.5Sn-Ti, and the maraging steel. Crack depth is plotted as a function of normalized output voltage. All curves begin with an output of 1 for a crack depth of 0.003 to 0.005 inch $(0.076$ to $0.13 \mathrm{~mm})$, which was the approximate crack depth when the reference output voltage was defined. All other output voltages were measured in multiples of the reference value. For each material, the curves obtained at both a high and a low stress are virtually identical (maximum difference of $0.002 \mathrm{in}$. or $0.05 \mathrm{~mm}$ ), which indicated that the output voltage for a given crack size is not affected by the cyclic stress level. Figure 6 indicates that, although the output voltage is apparently unaffected by the stress level, it is different for different materials. The ultrasonic crack-measuring apparatus, therefore, should be calibrated for each material before the device is to be used for monitoring crack growth.

The results of applying the ultrasonic technique in monitoring fatigue crack growth are shown in figure 5(c). Each dashed curve represents a particular crack depth. The data through which these curves are drawn were obtained by applying the ultrasonic device in conjunction with the calibration curves for the maraging steel. Figure 5(c) illustrates how the ultrasonic technique may be used to nondestructively measure increasing crack size as a function of cycles during a fatigue test. Such data can in turn be used to obtain fatigue crack-propagation rates. Thus, with this technique, crack-propagation rates as well as specimen fatigue life to fracture can be determined from a single test. 

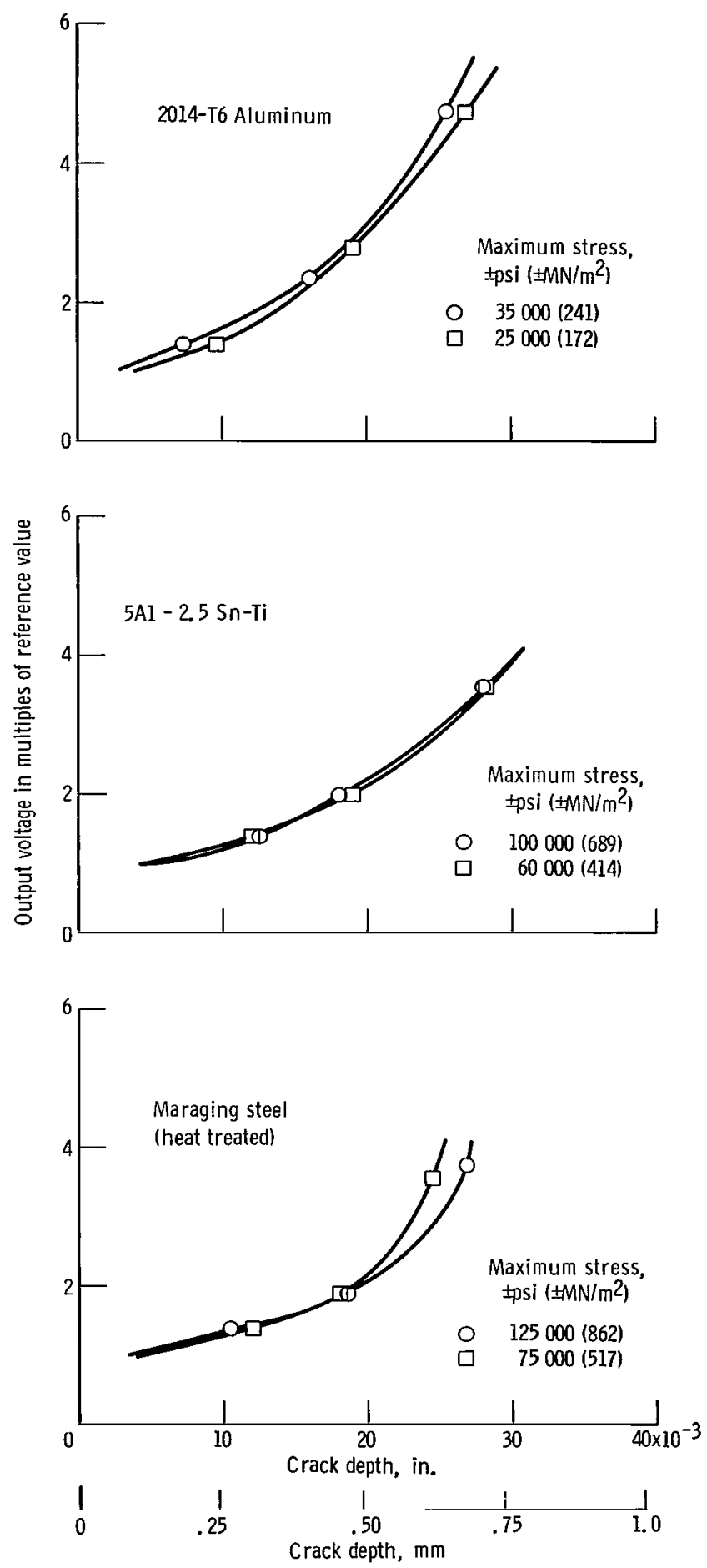

Figure 6. - Effect of crack depth on normalized output voltage of crack-detection device. 


\section{Metallographic Observations}

Photomicrographs of longitudinal sections of specimens tested to the initial detection of cracks for each material are presented in figure 7. Cracks emanate from the root of the notch and progress toward the center of the specimen, and cracks are generally transgranular. In most specimens, several cracks developed which began at different points along the notch root radius, as shown in figure 7 . This was most commonly observed in the 5Al-2.5Sn-Ti alloy, the maraging steel, and the cobalt-base alloy L-605. Cracks were also observed to emanate from the notch root at many points around the circumference of a given specimen. As the test progressed, these small cracks grew, some of them joining together to form the crack that eventually caused fracture.

When the applied cyclic stresses corresponded to those on the inclined portion of the fatigue curve (above the fatigue limit of the notched specimens), the main crack extended all the way around the specimen circumference and was generally uniform in depth until very rapid crack growth occurred just prior to fracture. This uniform crack growth is illustrated in figure 8, which shows fracture surfaces of maraging steel specimens tested to various stages of fatigue damage. This sequential series of macrographs was obtained after the specimens were fatigue tested to various values of output voltage as indicated by the ultrasonic detection device. They were then removed from the test and broken in tension. The fatigue-cracked portion of the fracture surface is clearly distinguishable in the figure as the lightly shaded area at the periphery of the 0.3 -inch(7. 6- $\mathrm{mm}-$ ) diameter test section. The dark, rough region in the center of the specimen represents the tensile fracture. The fatigue crack is not as apparent in specimens that were not tested beyond the point of initial crack detection (fig. 8(a) and (b)). However, microscopic examination showed that the crack extended around the entire circumference and that the depth varied between 0.001 and 0.003 inch $(0.025$ and $0.076 \mathrm{~mm})$ in both specimens shown. This represents a substantial variation, relative to the average crack depth of about 0.002 inch $(0.050 \mathrm{~mm})$. For larger cracks (figs. 8(c) - (h)), the crack depth was relatively uniform around the entire circumference. Note that the normalized output voltage for each specimen is the same for a given crack size, even though the number of applied cycles and the maximum cyclic stress level applied were different. These results indicate that the crack-detection system is sensitive to the crack area and independent of the way the crack was formed.

In figure 8, the main fatigue crack was shown to progress inward in a generally uniform manner around the entire circumference of the notched specimens when the applied cyclic stresses were high. This was not the case, however, when the maximum cyclic stress level was low, that is, when the level was in the region near the fatigue limit. Figure 9 shows the fracture surfaces of two maraging steel specimens tested at the relatively low stress level of $\pm 50000 \mathrm{psi}\left(345 \mathrm{MN} / \mathrm{m}^{2}\right)$. One of the tests (fig. $9(\mathrm{a})$ ) was 


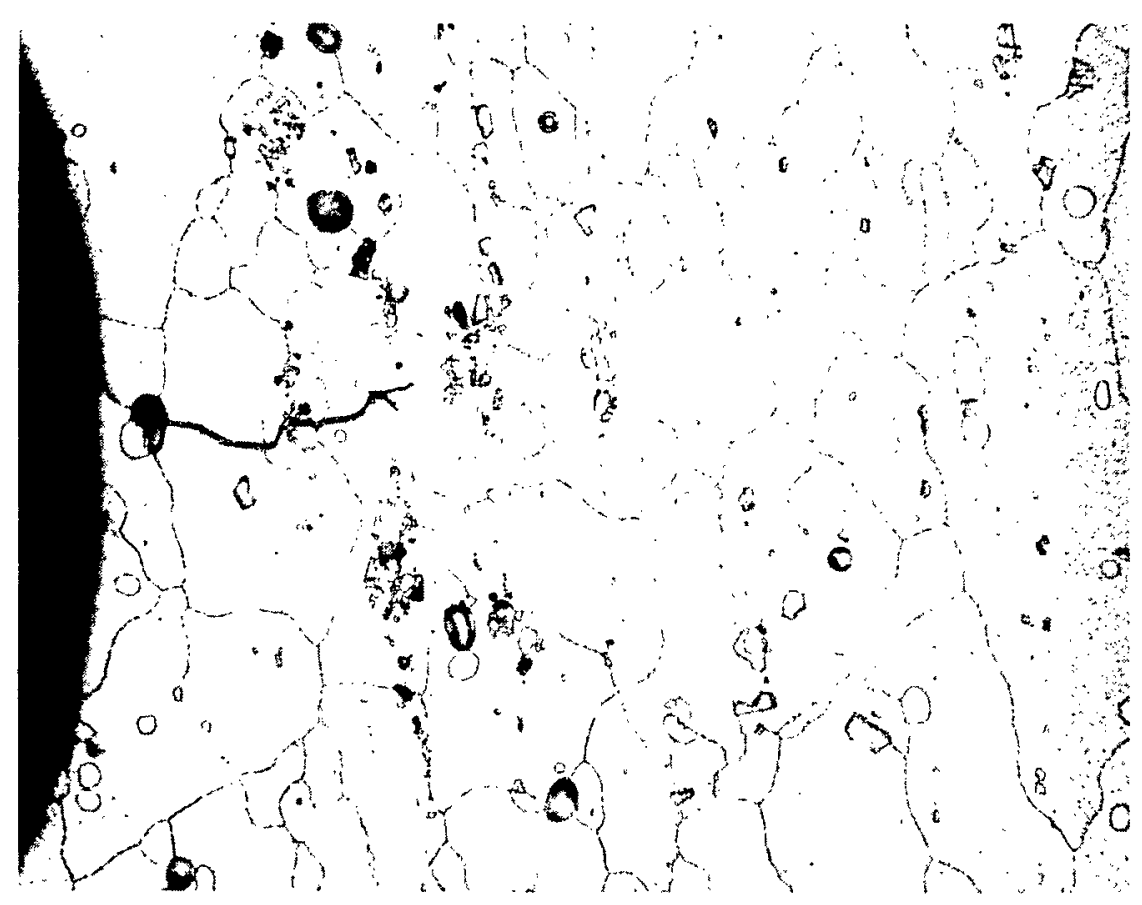

(a) 2014-T6 aluminum alloy.

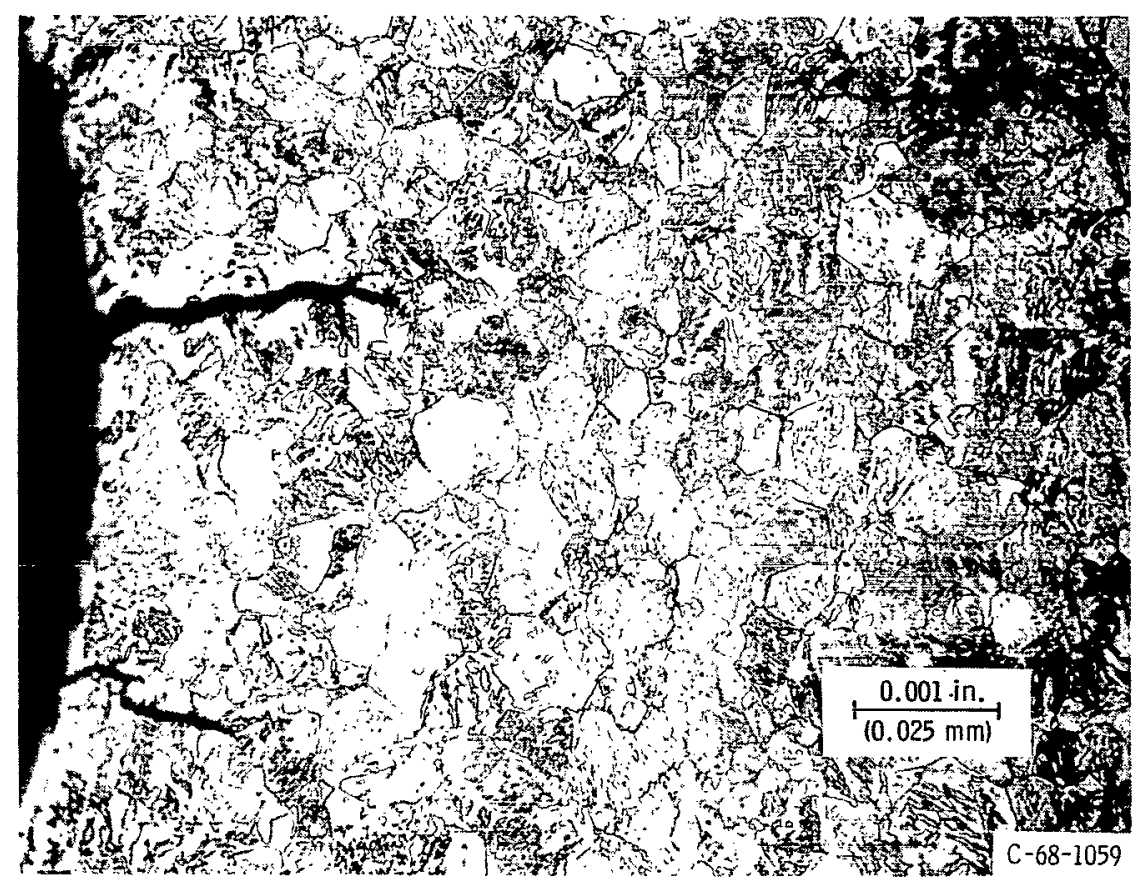

(b) 5Al-2.5 Sn-Ti alloy.

Figure 7. - Micrographs of tested fatigue specimens of each material showing first detectable cracks emanating from notch root. Longitudinal sections. 


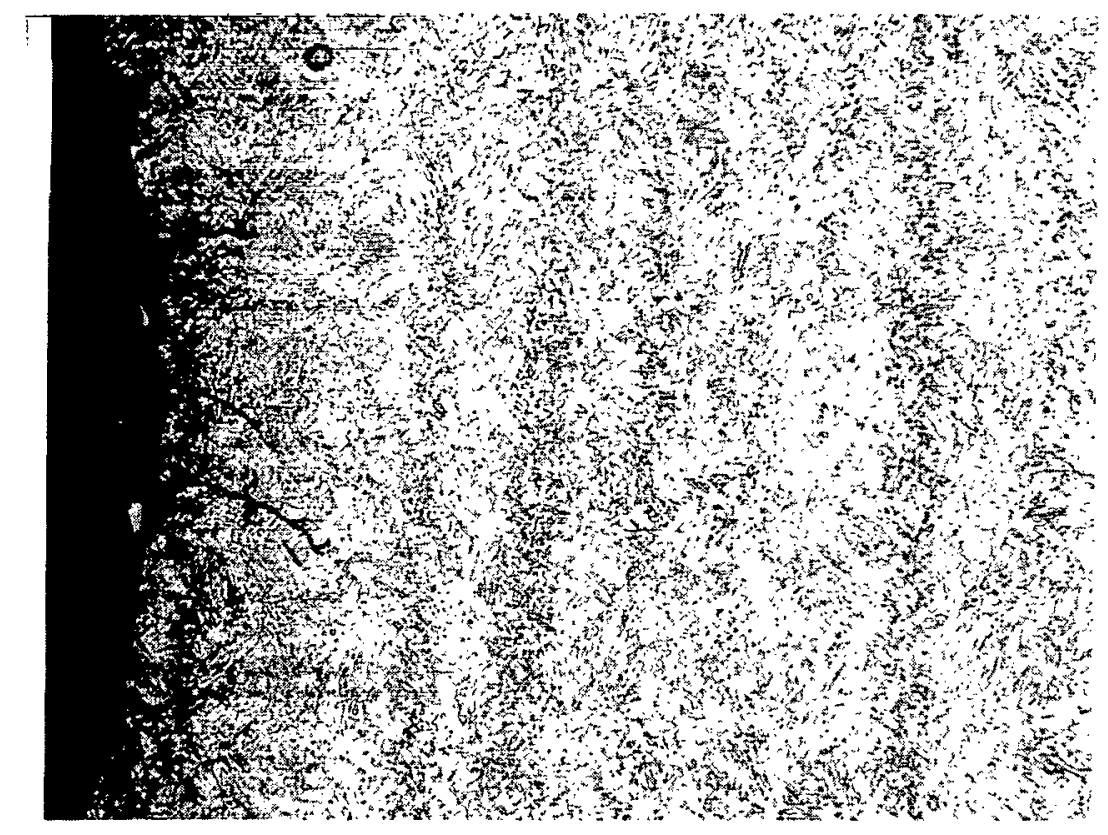

(c) Maraging steel (heat treated).

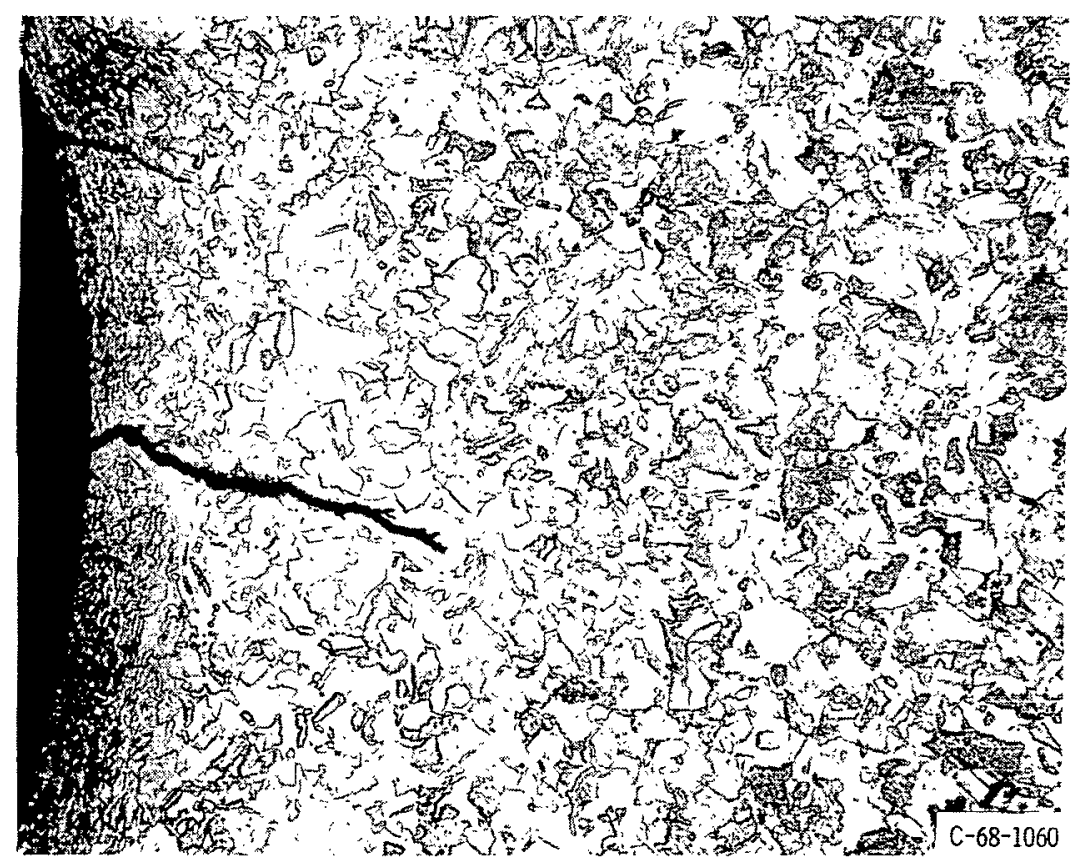

(d) Maraging steel (as-received).

Figu re 7. - Continued. 

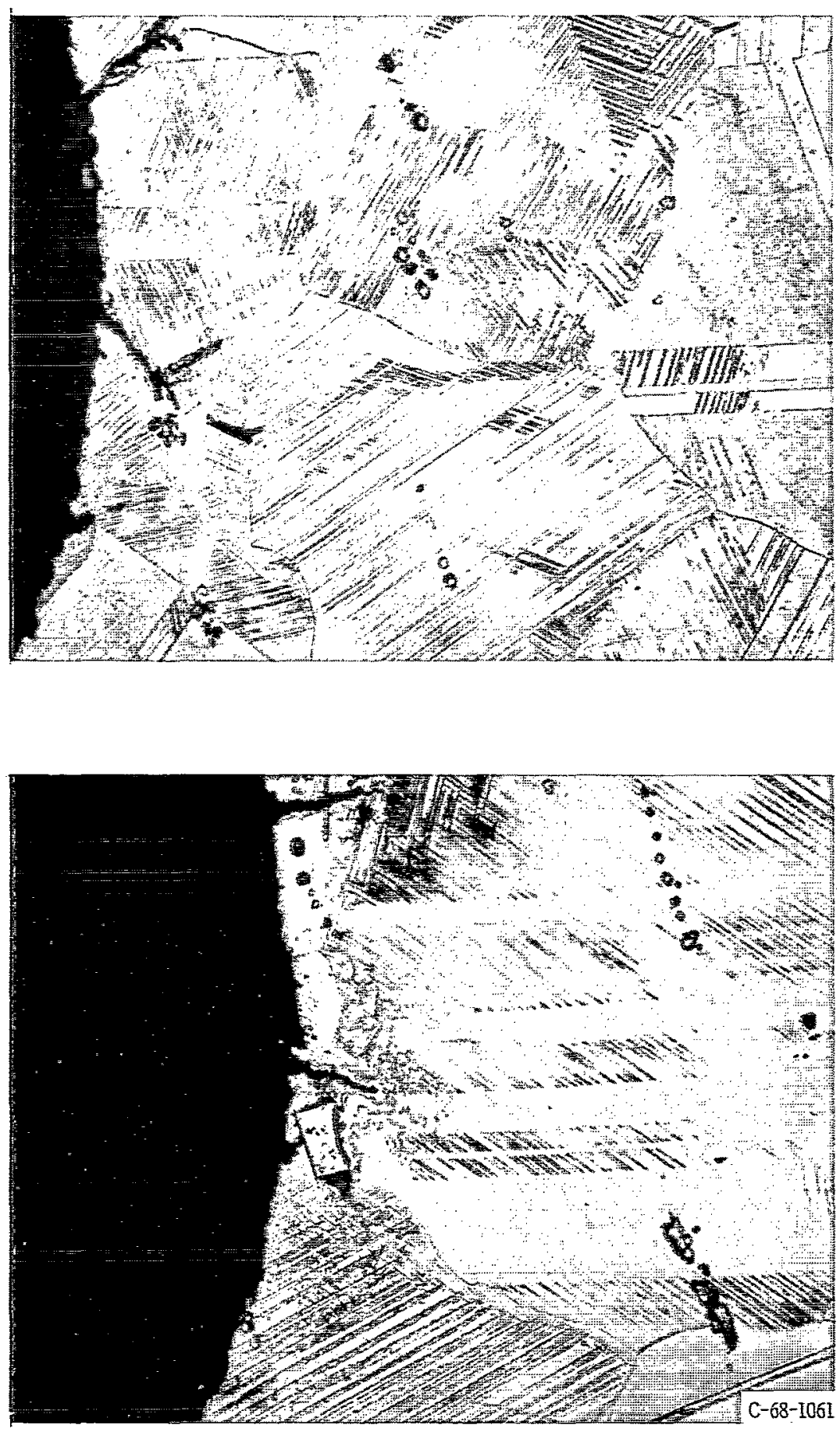

(e) Cobalt-base alloy L-605.

Figure 7. - Concluded. 


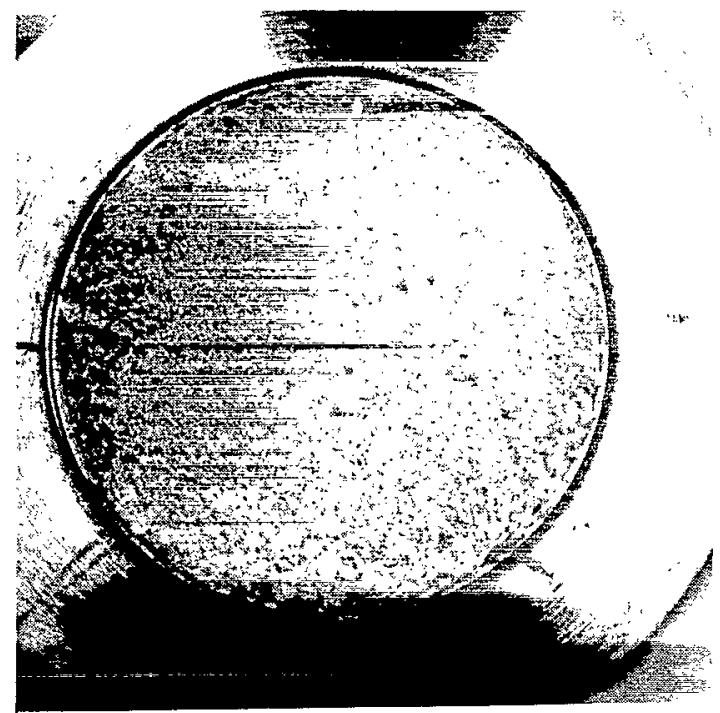

(a) Average crack depth, 0.0018 inch $(0.046 \mathrm{~mm})$; applied load cycles, 1103; normalized output voltage, <1.0; maximum cyclic stress, $\pm 75000 \mathrm{psi}\left( \pm 517 \mathrm{MN} / \mathrm{m}^{2}\right)$.

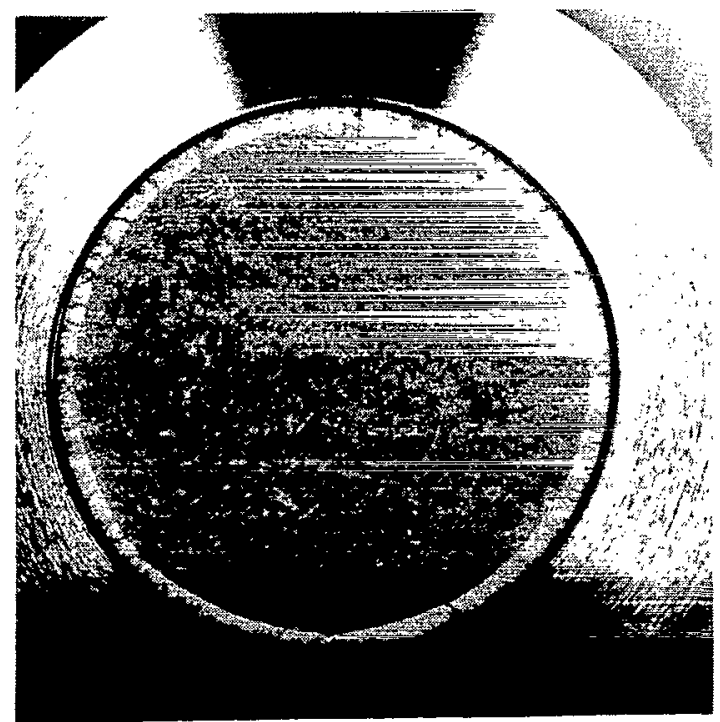

(c) Average crack depth, 0.0105 inch $(0.267 \mathrm{~mm})$; applied load cycles, 2883; normalized output voltage, 1.4; maximum cyclic stress, $\pm 75000 \mathrm{psi}\left( \pm 517 \mathrm{MN} / \mathrm{m}^{2}\right)$.

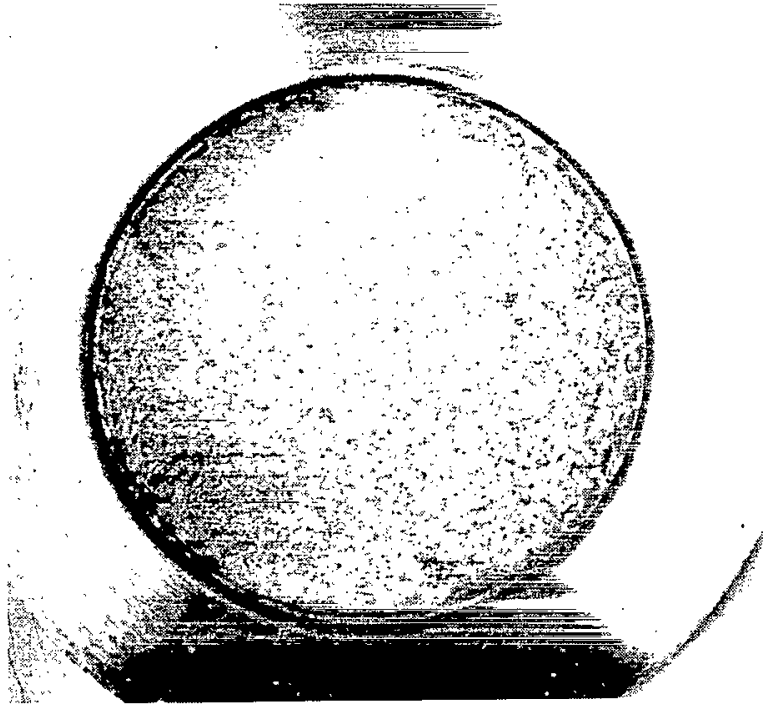

(b) Average crack depth, 0.0018 inch $(0.046 \mathrm{~mm})$; applied load cycles, 141; normalized output voltage, $<1.0$; maximum cyclic stress, $\pm 125000 \mathrm{psi}\left( \pm 862 \mathrm{MN} / \mathrm{m}^{2}\right)$.

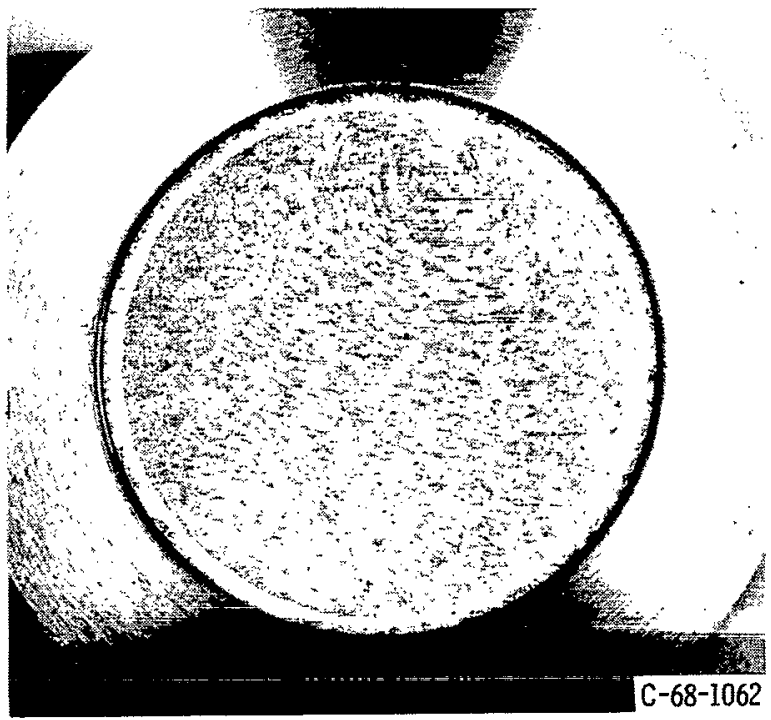

(d) Average crack depth, 0.0103 inch $(0.262 \mathrm{~mm})$; applied load cycles, 485; normalized output voltage, 1.4; maximum cyclic stress, $\pm 125000 \mathrm{psi}\left( \pm 862 \mathrm{MN} / \mathrm{m}^{2}\right)$.

Figure 8. - Fracture surfaces of maraging steel (heat treated) specimens showing crack depths corresponding to normalized output voltage of crack-detection system and applied cycles. Unetched. 


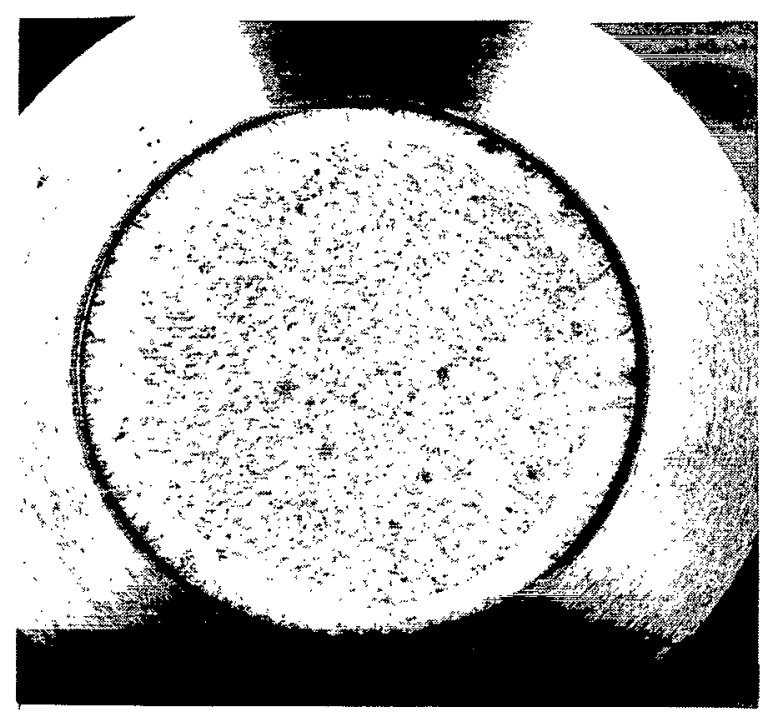

(e) Average crack depth, 0.0180 inch $(0.457 \mathrm{~mm})$; applied load cycles, 3492; normalized output voltage, 1.9; maximum cyclic stress, $\pm 75000 \mathrm{psi}\left( \pm 517 \mathrm{MN} / \mathrm{m}^{2}\right)$.

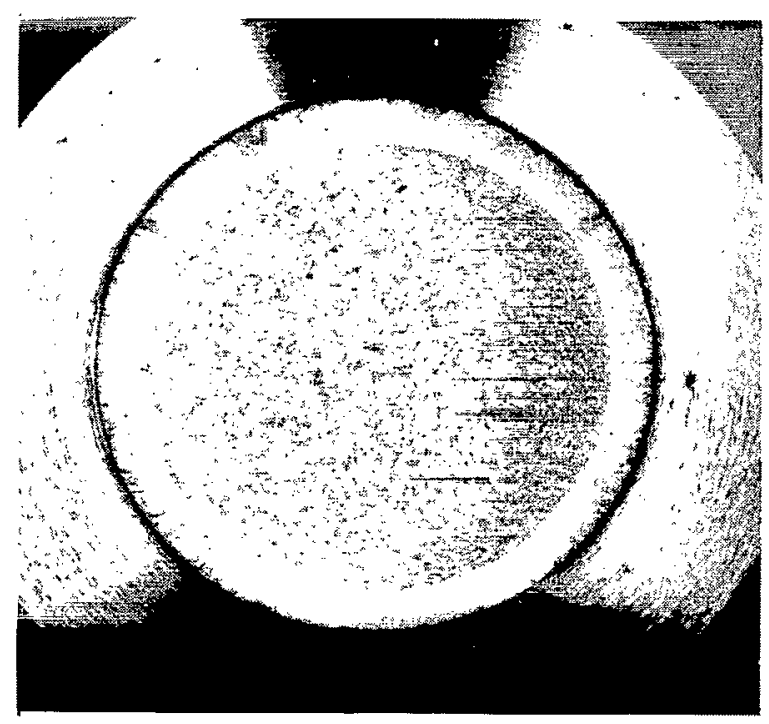

(g) Average crack depth, 0.0244 inch $(0.620 \mathrm{~mm})$; applied load cycles, 4177; normalized output voltage, 3.6; maximum cyclic stress, $\pm 75000 \mathrm{psi}\left( \pm 517 \mathrm{MN} / \mathrm{m}^{2}\right)$.

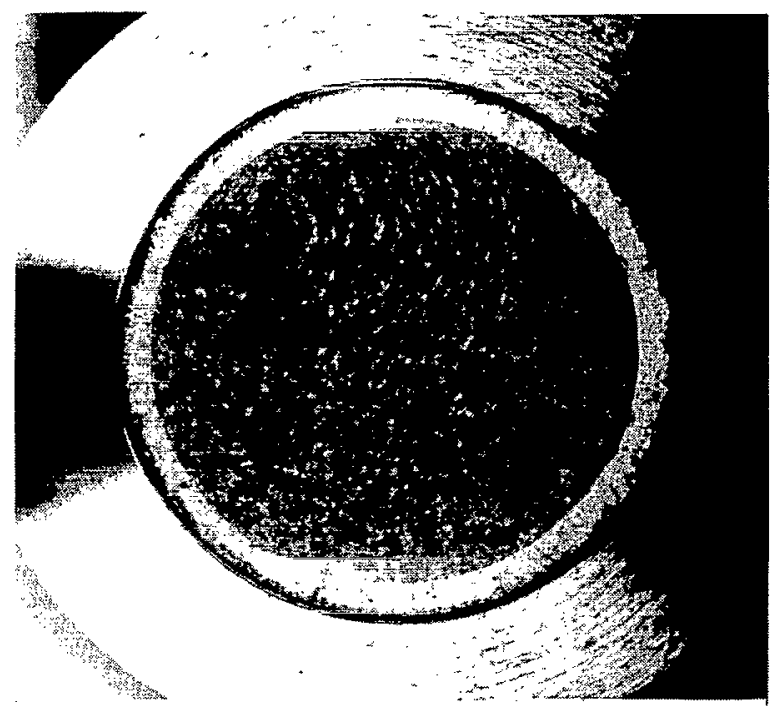

(f) Average crack depth, 0.0187 inch $(0.475 \mathrm{~mm})$; applied load cycles, 750; normalized output voltage, 1.9; maximum cyclic stress, \pm 125000 psi $\left( \pm 862 \mathrm{MN} / \mathrm{m}^{2}\right)$.

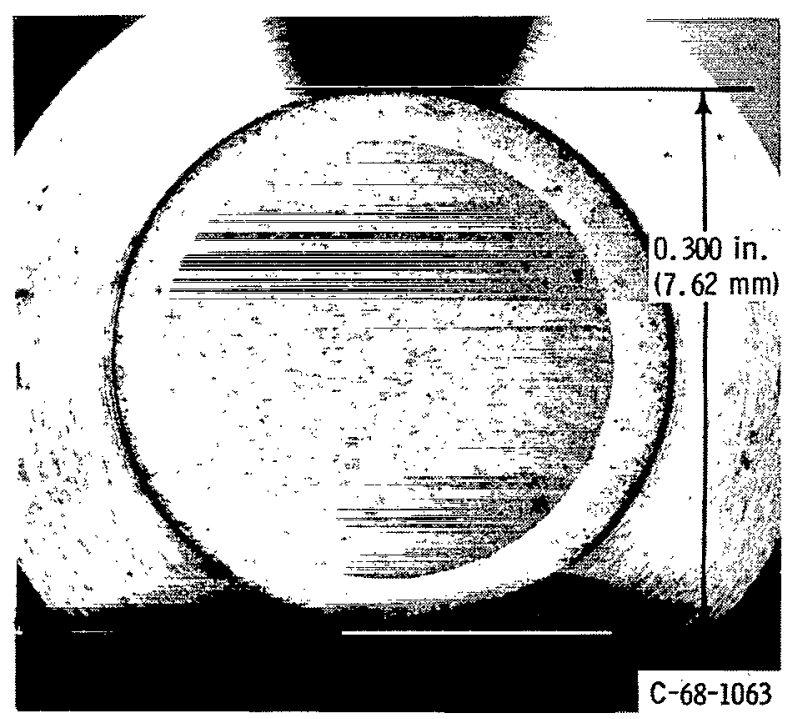

(h) Average crack depth, 0.0267 inch $(0.678 \mathrm{~mm})$; applied load cycles, 938; normalized output voltage, 3.75; maximum cyclic stress, $\pm 125000 \mathrm{psi}\left( \pm 862 \mathrm{MN} / \mathrm{m}^{2}\right)$.

Figure 8. - Concluded. 


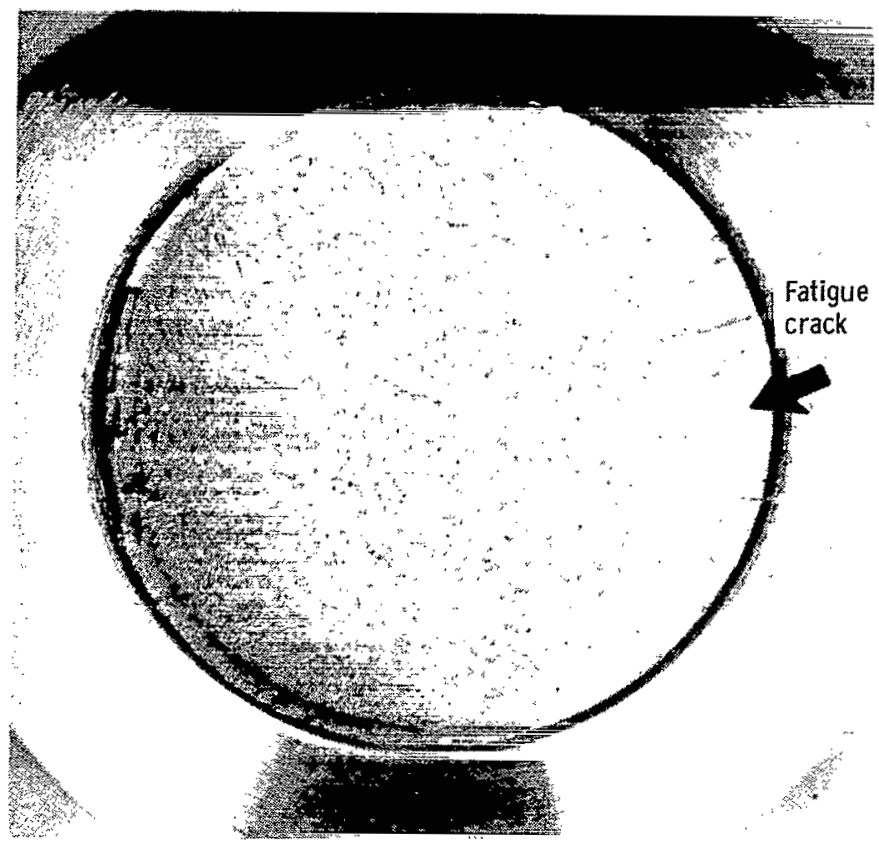

(a) Fatigue test stopped after 31450 cycles.

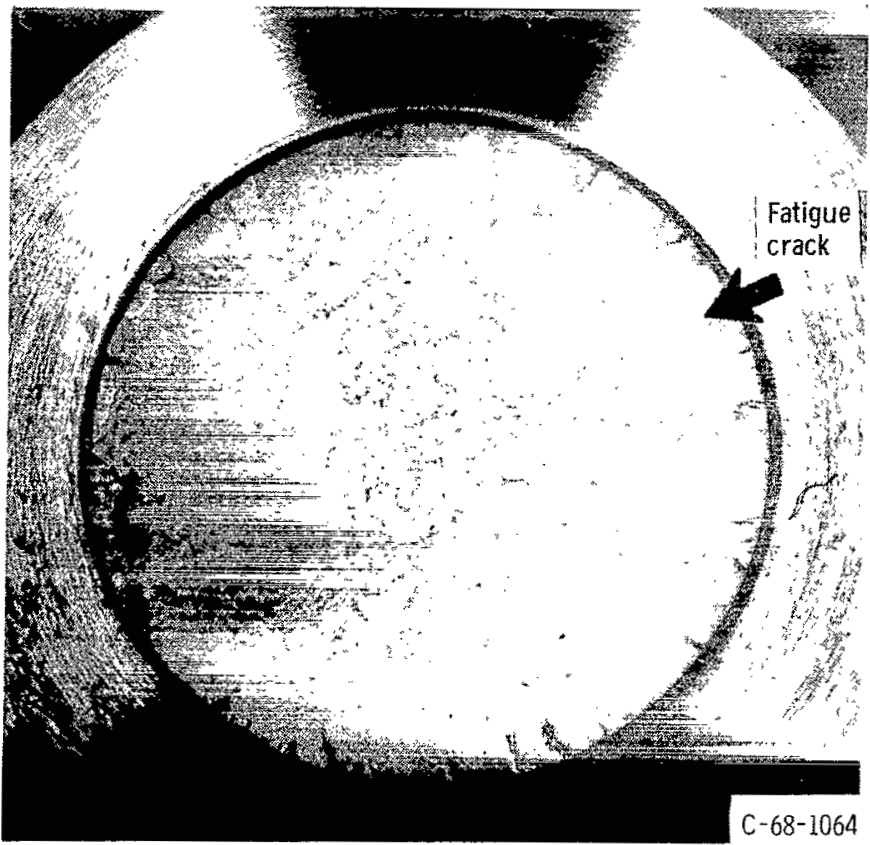

(b) Fatigue tested to fracture ( 37500 cycles).

Figure 9. - Fracture surfaces of maraging steel (heat treated) specimens tested near fatigue limit. Maximum cyclic stress, $\pm 50000 \mathrm{psi}\left( \pm 345 \mathrm{MN} / \mathrm{m}^{2}\right)$. 
stopped after operation for approximately 75 percent of the expected specimen life to fracture. After the specimen was removed from the test, it was broken in tension. In a second test (fig. 9(b)) the specimen was run to fracture. It is apparent from the macrographs of the fracture surfaces that fatigue cracking did not occur around the entire specimen circumference. Instead, the fatigue crack, which is evidenced by the smooth light surfaces, progressed primarily from one side of the specimen (see arrows in fig. 9).

\section{SUMMARY OF RESULTS}

An ultrasonic method was developed to detect and measure fatigue cracks nondestructively, during test, in notched cylindrical specimens subjected to reversed axial fatigue loading. The reflection technique was employed. The specimens contained a circumferential notch that provided a theoretical stress concentration $\mathrm{K}_{\mathrm{t}}$ of 3.65 . Materials used were 2014-T6 aluminum, 5Al-2.5Sn-Ti, a maraging steel, and a cobaltbase alloy L-605. Fatigue curves were obtained showing cycles to initially detectable cracks as well as cycles to fracture. The following results were obtained:

1. The depth of initially detectable cracks, which generally extended around the specimen circumference, was approximately 0.0005 to 0.004 inch (0.013 and $0.10 \mathrm{~mm})$ for the materials used. Smaller cracks can be detected with this method by introducing additional refinements in operating techniques.

2. For the specimen geometry investigated, initially detectable cracks were formed within approximately 10 to 40 percent of life to fracture depending on the material and the cyclic stress.

3. Crack depths up to approximately 0.030 inch $(0.76 \mathrm{~mm})$ were reproducibly meas ured with the ultrasonic method, which suggests that this technique can provide a convenient means of monitoring fatigue crack growth in notched specimens during test.

4. The curves of output voltage as a function of crack depth were virtually the same for a given material regardless of cyclic stress level. However, these calibration curves were different for the different materials.

5. For all materials investigated, the fatigue cracks were generally transgranular.

6. At stresses above the region of the fatigue limit (inclined portion of the fatigue curve), the fatigue macrocrack front advanced uniformly from points around the specimen circumference until a point of rapidly accelerated crack growth was reached. At lower stresses, near the fatigue limit of the notched specimens, the crack that caused fracture usually propagated from one side.

\section{Lewis Research Center,}

National Aeronautics and Space Administration, Cleveland, Ohio, June 3, 1968, 129-03-07-01-22. 


\section{REFERENCES}

1. Feinstein, L.; and Hruby, R. J.: Surface Crack Detection by Microwave Methods. Presented at Sixth Symposium on Nondestruction Evaluation of Aerospace and

Weapons Systems Components and Materials, San Antonio, Texas, Apr. 17-19, 1967.

2. Klima, Stanley J.; Lesco, Daniel J.; and Freche, John C.: Ultrasonic Technique for Detection and Measurement of Fatigue Cracks. NASA TN D-3007, 1965.

3. Rasmussen, J. G.: Prediction of Fatigue Failure Using Ultrasonic Surface Waves. J. Soc. Nondestructive Testing, vol. 20, no. 2, Mar-Apr. 1962, pp. 103-110.

4. Rublev, Ya. A.; and Danilov, Yu. S.: Ultrasonic Detection of Fatigue Cracks During Repeated Static Tests. Industrial Lab., vol. 29, Apr. 1964, pp. 1306-1309.

5. Hinsley, J. F.: Non-Destructive Testing. MacDonald and Evans, Ltd., London, 1959.

6. Carlin, Benson: Ultrasonic. Second ed., McGraw-Hill Book Co., Inc., 1960.

7. Banks, B.; Oldfield, G. E.; and Rawding, H.: Ultrasonic Flaw Detection in Metals. Iliffe Books Ltd., London, 1962.

8. Anon.: Manual on Fatigue Testing. Spec. Tech. Publ. No. 91, ASTM, 1949, p. 33. 


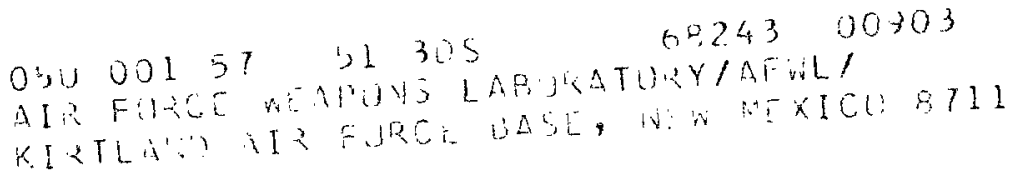

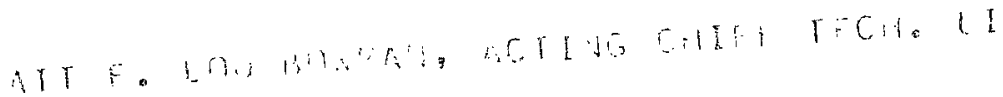

"The aeronatical and space activities of the United States shall be conducted so as to contribute. . . to the expansion of buman knowledge of phenomena in the atmosphere and space. The Administration shall provide for the widest practicable and appropriate dissemination of information concerning its activities and the results thereof."

- National Aeronautics And Space ACt of 1958

\section{NASA SCIENTIFIC AND TECHNICAL PUBLICATIONS}

TECHNICAL REPORTS: Scientific and technical information considered important, complete, and a lasting contribution to existing knowledge.

TECHNICAL NOTES: Information less broad in scope but nevertheless of importance as a contribution to existing knowledge.

TECHNICAL MEMORANDUMS: Information receiving limited distribution because of preliminary data, security classification, or other reasons.

CONTRACTOR REPORTS: Scientific and technical information generated under a NASA contract or grant and considered an important contribution to existing knowledge.
TECHNICAL TRANSLATIONS: Information published in a foreign language considered to merit NASA distribution in English.

SPECIAL PUBLICATIONS: Information derived from or of value to NASA activities. Publications include conference proceedings, monographs, data compilations, handbooks, sourcebooks, and special bibliographies.

\section{TECHNOLOGY UTILIZATION}

PUBLICATIONS: Information on technology used by NASA that may be of particular interest in commercial and other non-aerospace applications. Publications include Tech Briefs, Technology Utilization Reports and Notes, and Technology Surveys.

Details on the availability of these publications may be obtained from: 